\title{
Autophagy and autophagy-related proteins in the immune system
}

\author{
Shibutani, Shusaku T ; Saitoh, Tatsuya ; Nowag, Heike ; Münz, Christian ; Yoshimori, Tamotsu
}

\begin{abstract}
Autophagy is an intracellular bulk degradation system that is highly conserved in eukaryotes. The discovery of autophagy-related ('ATG') proteins in the 1990s greatly advanced the mechanistic understanding of autophagy and clarified the fact that autophagy serves important roles in various biological processes. In addition, studies have revealed other roles for the autophagic machinery beyond autophagy. In this Review, we introduce advances in the knowledge of the roles of autophagy and its components in immunity, including innate immunity, inflammatory responses and adaptive immunity.
\end{abstract}

DOI: https://doi.org/10.1038/ni.3273

Posted at the Zurich Open Repository and Archive, University of Zurich

ZORA URL: https://doi.org/10.5167/uzh-118134

Journal Article

Accepted Version

Originally published at:

Shibutani, Shusaku T; Saitoh, Tatsuya; Nowag, Heike; Münz, Christian; Yoshimori, Tamotsu (2015). Autophagy and autophagy-related proteins in the immune system. Nature Immunology, 16(10):10141024.

DOI: https://doi.org/10.1038/ni.3273 


\section{Autophagy and autophagy-related proteins in the immune system}

Shusaku T. Shibutani ${ }^{1,2,5}$, Tatsuya Saitoh ${ }^{3}$, Heike Nowag ${ }^{4}$, Christian Münz ${ }^{4}$, and Tamotsu Yoshimori ${ }^{1,2}$

${ }^{1}$ Laboratory of Intracellular Membrane Dynamics, Graduate School of Frontier Biosciences, Osaka University, Osaka 565-0871, Japan

${ }^{2}$ Department of Genetics, Graduate School of Medicine, Osaka University, Osaka 565-0871, Japan

${ }^{3}$ Division of Molecular Genetics, The Institute for Enzyme Research, Tokushima University, Tokushima 770-8503, Japan

${ }^{4}$ Viral Immunobiology, Institute of Experimental Immunology, University of Zürich, 8057 Zürich, Switzerland

${ }^{5}$ Present address: Laboratory of Veterinary Hygiene, Joint Faculty of Veterinary Medicine, Yamaguchi University, Yamaguchi 753-8515 Japan

Correspondence: Tamotsu Yoshimori

Tel: +81-6-6879-3580; Fax: +81-6-6879-3589

E-mail: tamyoshi@fbs.osaka-u.ac.jp 


\section{Abstract}

Autophagy is an intracellular bulk degradation system that is highly conserved in eukaryotes. The discovery of Atg proteins in the 1990s has greatly advanced our mechanistic understanding of autophagy, which allowed us to understand that autophagy plays important roles in various biological processes. In addition, recent studies revealed other roles of the autophagic machinery beyond autophagy. In this review, we introduce recent advances in our knowledge of the roles that autophagy and its components play in immunity, including innate immunity, inflammation responses, and adaptive immunity.

\section{Introduction}

In macroautophagy (hereafter referred to as "autophagy"), a double-membrane organelle called the autophagosome plays a central role. Autophagosome formation is maintained at relatively low levels under non-stress conditions, and is induced dramatically by various cellular stresses (e.g. amino acid starvation). As shown in Figure 1, autophagosome formation starts with the emergence of a membrane cup called the isolation membrane (also called the phagophore). The isolation membrane elongates and closes, resulting in the formation of a double-membranous autophagosome, which engulfs a portion of the cytoplasm. Then the subsequent autophagosome-lysosome fusion leads to the digestion of its content and inner membrane by lysosomal hydrolases (Figure 1).

A growing body of evidence suggests that autophagy plays important roles in various biological processes at cellular and physiological levels, and is generally beneficial to cells/organisms(Mizushima and Komatsu, 2011). Furthermore, it became also clear that proteins involved in autophagy have other functions than autophagy. In this review, we will discuss recent advances in our understanding of autophagy and its machinery in relation to innate immunity, inflammatory responses, and adaptive immunity.

\section{Atg proteins}

Although autophagic structures were already reported in electron microscopy studies in the 1950s, the molecular mechanism of autophagy remained mostly unknown until the discovery of yeast ATG genes in the 1990s(Clark, 1957; Novikoff, 1959; Ohsumi, 2014). 38 ATG genes have been identified so far, and the 15 core ATG genes in yeast (ATG1-10,12-14, 16, 18) are conserved in mammals, indicating that autophagy is an evolutionarily conserved process. As in yeast, mammalian core Atg proteins can be classified into several functional units: the ULK complex, Atg9L, the class III PI3K complex, the Atg2-WIPI complex, the Atg12 conjugation system, and the LC3 conjugation system. 


\section{Functions of Atg proteins}

The ULK complex (a Ser/Thr kinase complex composed of ULK1/2, Atg13, Atg101, and FIP200) and Atg9L (Atg9L1/2) are thought to act most upstream of autophagy(Itakura and Mizushima, 2010). The activity of the ULK complex is regulated negatively by mTORC1 and positively by AMPK. Both the ULK complex and Atg9L1 are required for the recruitment of the autophagy-specific class III PI3 kinase (PI3K) complex(Itakura and Mizushima, 2010; Kageyama et al., 2011).

PI3Ks are lipid kinases that phosphorylate phosphatidylinositol (PI) at the position 3 hydroxyl group of the inositol ring, resulting in the generation of phosphatidylinositol 3-phosphate (PI3P). The autophagy-specific PI3K complex is composed of Atg14L, Vps34 (catalytic subunit), Beclin 1, and Vps15 (hereafter called the Atg14L complex). Atg14L localizes on the endoplasmic reticulum (ER), and its ER localization is required for its autophagy-inducing ability(Matsunaga et al., 2010). The Atg14L complex accumulates at the ER-mitochondria contact sites upon starvation, which requires Syntaxin 17, a SNARE protein that resides on the ER and mitochondria(Hamasaki et al., 2013). It is likely that the Atg14L complex generates PI3P on the ER at the ER-mitochondria contact site to generate the platform for isolation membrane formation. PI3P generation provides the binding site for PI3P-binding proteins, including WIPIs (WIPI1-4: the mammalian orthologues of yeast Atg18). WIPIs form a complex with Atg2 (Atg2A/B). A recent study has shown that WIPI2 directly binds to Atg16L1 and recruits the Atg16L1 complex to the autophagosome formation site(Dooley et al., 2014).

The Atg16L1 complex (composed of Atg16L1, Atg5, and Atg12) specifically localizes to the isolation membrane and dissociates from it upon the completion of autophagosome formation(Mizushima et al., 2001). The ubiquitin-like protein $\operatorname{Atg} 12$ is covalently conjugated to Atg5 by Atg7 (E1-like enzyme) and Atg10 (E2-like)(Nakatogawa et al., 2009). Atg16L1 and Atg12-Atg5 form a 2:2:2 complex(Fujita et al., 2009). The Atg16L1 complex functions as the E3-like enzyme for the other ubiquitin-like system: LC3-PE(Nakatogawa et al., 2009). There are seven mammalian orthologues of Atg8 (LC3A/B/C, GABARAP, and GABARAPL1/2/3; represented by LC3 in this review). LC3 is conjugated to the membrane lipid molecule phosphatidylethanolamine (PE) by Atg7 (E1-like) and Atg3 (E2-like)(Nakatogawa et al., 2009). LC3-PE conjugation takes place at the isolation membrane, where the Atg16L1 complex (E3-like) accumulates(Fujita et al., 2008b, 16). LC3 is widely used as a marker for microscopic detection of isolation membranes and autophagosomes. In addition, PE-conjugated LC3 (LC3- II) and unconjugated LC3 (LC3- I ) can be separately detected by Western blot, and the amount of LC3- II is also widely used to quantify autophagic activity(Kabeya et al., 2000). It is suggested that LC3 functions in the closure of the isolation membrane(Fujita et al., 2008a, 4; Sou et al., 2008). 


\section{Autophagy and pathogen infection}

Autophagy has been studied in relationship to infection by bacteria, viruses, and parasites. As described in Box 1, a number of in vivo studies have shown that autophagy serves a protective function against pathogens. Other studies suggest that autophagy suppresses excessive inflammatory responses upon pathogen infection. The relationship between autophagy and inflammation will be discussed later in this review.

\section{Regulation of the autophagy machinery by immune signals}

Autophagy is also regulated by a plethora of immune signals, including ligands for pattern-recognition receptors (e.g. Toll-like receptors (TLRs) and Nod-like receptors (NLRs)) and cytokines (Box 2). In addition, the stimulation of phagocytes by particles coated with TLR ligands also induces LC3 lipidation on phagosomal membranes. This phenomenon is called LC3-associated phagocytosis (LAP) (Figure 2). It should be noted that LAP phagosomes (single membrane) are different from autophagosomes (double membrane), and that the fluorescence microscopic detection of LC3 should be carefully interpreted because it cannot distinguish these two structures. Although LAP was initially shown to facilitate phagosome-lysosome fusion and accelerates pathogen killing(Sanjuan et al., 2007), further investigation revealed various functions of LAP beyond the acceleration of pathogen killing, including antigen presentation (discussed below in the adaptive immunity section).

Although the examples in Box 1 and 2 indicate that the role of autophagy in the protection from pathogen infection in vivo is likely to be complex, the most direct way of autophagy-dependent pathogen elimination is the engulfment of pathogen by the autophagosome and the subsequent pathogen killing by lysosome-autophagosome fusion.

\section{Discovery of xenophagy}

Autophagy was initially thought to be a non-specific degradation process. However, it is now apparent that autophagy has an ability to selectively target large structures such as intracellular pathogens, damaged organelles, and protein aggregates. This type of autophagy, called selective autophagy, is thought to maintain intracellular homeostasis by eliminating unwanted structures. In particular, selective autophagy against pathogens is called xenophagy.

Anti-bacterial xenophagy both in non-phagocytic and phagocytic cells has been extensively investigated. In the case of phagocytes such as macrophages, dendritic cells, and neutrophils, bacteria are recognized by pattern-recognition receptors on their surface, leading to the activation of intracellular signaling that leads to immune responses. At the same time, bacteria are internalized by phagocytosis, and effectively killed by phagosome-lysosome fusion as well as the exposure to reactive oxygen species and antimicrobial peptides(Flannagan et al., 2009). However, invasive bacteria, such as Salmonella, Listeria, 
and Shigella, invade non-phagocytic cells (e.g. intestinal epithelium). They modify endosomes into the niche suitable for their survival and proliferation, and often break into the nutrient-rich cytosol from the vacuole(Cossart and Sansonetti, 2004).

Xenophagy against invasive bacteria in non-phagocytic cells was demonstrated in 2004 by Nakagawa et al(Nakagawa et al., 2004). This study showed that Group A Streptococcus (GAS) is efficiently targeted by LC3-positive, autophagosome-like double membrane structure and is later subjected to lysosomal degradation. Moreover, the genetic deletion of Atg5 resulted in the absence of the LC3-positive structure and in increased GAS survival. This study clearly showed that autophagy functions as an intracellular innate immune system against bacterial invasion in non-phagocytic cells. Around the same time, it was shown that the survival of Mycobacterium bovis BCG and Mycobacterium tuberculosis in macrophages is suppressed by autophagy induction(Gutierrez et al., 2004). Follow-up studies have shown that other invasive bacteria, including Shigella flexneri(Ogawa et al., 2005), Salmonella Typhimurium(Birmingham et al., 2006), and Listeria monocytogenes(Py et al., 2007), are also targeted by autophagy.

On the other hand, there are bacterial species that have evolved mechanisms to prevent autophagy in a strain-specific manner, and therefore become more vulnerable to antibacterial xenophagy when these self-defense mechanisms are impaired. These bacteria include Shigella flexneri, Listeria monocytogenes, and Legionella pneumophila as reviewed in detail elsewhere(Huang and Brumell, 2014).

\section{Mechanisms of anti-bacterial xenophagy: ubiquitination of the substrate}

The key event that triggers anti-bacterial xenophagy and other selective autophagy is ubiquitination (the covalent conjugation of ubiquitin to the substrate). Ubiquitination is mediated by E1 (ubiquitin-activating enzyme), E2 (ubiquitin-conjugating enzyme), and E3 (ubiquitin ligase). E3 ubiquitin ligases recognize substrates and therefore determine substrate specificity. Ubiquitination has been well characterized as a hallmark event in the ubiquitin-proteasome pathway, which degrades individual ubiquitinated proteins by the proteasome(Welchman et al., 2005). However, recent studies have shown its involvement in selective autophagy. Notably, the artificial ubiquitin tagging to monomeric red fluorescent protein (mRFP) or peroxisomes leads to autophagic degradation of mRFP or peroxisomes, respectively(Kim et al., 2008). Moreover, invasive bacteria often colocalize with ubiquitin(Fujita and Yoshimori, 2011). Two E3 ubiquitin ligases have been related to anti-bacterial xenophagy so far: LRSAM1(Ng et al., 2011; Huett et al., 2012) and Parkin(Manzanillo et al., 2013). Parkin is also known as the major E3 ubiquitin ligase responsible for mitophagy (selective autophagy of mitochondria)(Narendra et al., 2008).

One possible mechanism underlying the bacteria-ubiquitin colocalization may be the direct ubiquitination of bacteria, and an alternative possibility is the ubiquitination of bacteria-containing endosomes. Several studies support the latter model. The endosomal 
membrane is ubiquitinated after Shigella flexneri escapes into the cytosol from the endosome(Dupont et al., 2009). Salmonella Typhimurium inside endosomes was found to be targeted by autophagosomes(Birmingham et al., 2006; Kageyama et al., 2011). Strikingly, even endocytosed latex beads can induce autophagosome formation after the bead-containing endosomal membrane is ruptured(Kobayashi et al., 2010; Fujita et al., 2013), suggesting that no bacterial factors are required for selective autophagosome formation. Moreover, the rupture in lysosomal membrane induces selective ubiquitination and autophagy of the ruptured lysosome (named lysophagy)(Hung et al., 2013; Maejima et al., 2013). An important insight from these results is that cells may be simply detecting the rupture in pathogen-containing endosomes as an autophagy-inducing signal rather than preparing different autophagy-inducing mechanisms for various kinds of pathogens.

\section{Ubiquitination-dependent and -independent recruitment of LC3 through autophagy adaptor proteins}

How can ubiquitination function as the signal for selective autophagy? Autophagy adaptor (receptor) proteins such as p62, NDP52, and optineurin have been suggested to play an important role in xenophagy against intracellular bacteria(Huang and Brumell, 2014). These adaptor proteins contain ubiquitin-binding domains and LC3-interacting regions (LIRs), and therefore it is proposed that the adaptor proteins recruit the LC3 machinery to ubiquitinated substrates (Figure 2). In addition, NDP52 binds galectin-8, a $\beta$-galactose binding lectin. Since $\beta$-galactose chains exist in the lumen of endosomes, galectin- 8 and its binding partner NDP52 are recruited from the cytoplasm to the endosomal membrane when the endosome is ruptured(Thurston et al., 2012).

\section{Ubiquitination-dependent recruitment of Atg proteins}

However, even in the absence of LC3 recruitment to intracellular Salmonella (in Atg3, 5, and 7 knockout cells) isolation membrane formation can initiate around Salmonella-containing endosomes(Kageyama et al., 2011). In the absence of LC3 recruitment, other Atg proteins such as the ULK1 complex and Atg9L1 are recruited to intracellular Salmonella, suggesting that the recruitment of these early Atg proteins is sufficient for the start of isolation membrane formation independently of the adaptor protein-mediated recruitment of LC3(Kageyama et al., 2011), although these isolation membranes cannot mature to complete autophagosome without LC3-PE. A follow-up study revealed that the recruitment of the ULK1 complex, Atg9L1, and the Atg16L1 complex (and the downstream Atg proteins Atg14L, WIPI1, and LC3) to ruptured endosomes is all dependent on ubiquitination(Fujita et al., 2013). The recruitment of the Atg16L1 complex involves the direct Atg16L1-ubiquitin binding through the C-terminal WD domain of Atg16L1 and the direct Atg16L1-FIP200 binding (FIP200 is a subunit of the ULK1 complex)(Fujita et al., 2013). The exact mechanisms for ubiquitination-dependent recruitment of the ULK1 complex and Atg9L1 remain unknown. 


\section{Xenophagy against viruses}

The role of autophagy in virus infection is complex and dependent on the virus. Although several viruses have autophagy-inhibitory functions, and even exploit autophagy for their replication(Dreux and Chisari, 2010; Yordy et al., 2013), it has been shown that the virulence of several viruses is suppressed by autophagy. For example, capsid proteins of Sindbis virus are degraded by autophagy in a p62-dependent manner, and neuron-specific Atg5-knockout mice exhibit higher susceptibility to the virus infection(Liang et al., 1998; Orvedahl et al., 2010). The following genome-wide siRNA screening identified 141 genes, the knockdown of which affects the colocalization of Sindbis virus capsid protein with GFP-LC3. One of those genes, SMURF1, was shown to be required for cell survival after Sindbis virus and herpes simplex virus type 1 (HSV-1) infection(Orvedahl et al., 2011).

The human immunodeficiency virus type 1 (HIV-1) virulence factor Nef has been shown to suppress autophagy by binding to Beclin 1(Kyei et al., 2009). A recent study showed that the Nef-binding sequence of Beclin 1 (amino acids 267-284) induces autophagy when modified as a cell-permeable peptide (Tat-Beclin 1). Tat-Beclin 1 was shown to suppress Sindbis virus, Chikungunya virus, and West Nile virus, and HIV-1 in vitro, and reduced lethality of infection by Chikungunya virus and West Nile virus in vivo(Shoji-Kawata et al., 2013).

\section{Autophagy in innate immunity}

The innate immune system induces inflammation to protect a host from microbial infection(Kawai and Akira, 2009). Pattern-recognition receptors (PRRs) sense microbial components and induce activation of signal transduction pathways leading to expression of inflammatory mediators such as cytokines and type I interferons (IFNs). Although inflammation is essential for host defense, aberrant induction of inflammation causes the development of inflammatory diseases, such as septic shock, autoimmune diseases and metabolic diseases. Thus, the innate immune system is strictly regulated to avoid either insufficient or excessive inflammatory responses. Accumulating evidence has shown that intracellular degradation system plays an important role in regulation of inflammatory responses. In particular, recent studies have shown the involvement of autophagy in inflammatory responses(Deretic et al., 2013).

\section{Inflammasome}

The inflammasome is a cytosolic protein complex consisting of NOD-like receptors (NLRs) or of the absent in melanoma 2 (AIM2) protein together with the adaptor protein apoptosis-associated speck-like protein containing caspase recruitment domain (ASC) and the protease caspase-1(Latz et al., 2013). Inflammasome activation induces proteolytic 
maturation of interleukin (IL)- $1 \beta$ and the related cytokine IL-18 by caspase- 1 , which in turn induces production of these cytokines. Inflammasomes drive cytokine-dependent host defense against microbes. However, aberrant activation of inflammasomes by an excess of microbial components, host-derived stimulatory factors and environmental irritants often causes massive inflammation, resulting in severe tissue damage. Hence, inflammasomes are strongly associated with the development of infectious and inflammatory diseases.

\section{Autophagy in production of IL-1 $\beta$ and IL-18}

Genome-wide association studies have identified ATG16L1 as a genetic factor responsible for susceptibility to Crohn's disease, a chronic inflammatory disease of the intestine(Hampe et al., 2007; Rioux et al., 2007). The importance of ATG16L1 in maintenance of intestinal homeostasis has been confirmed in mouse models. Hematopoietic cell-specific ATG16L1-deficient mice and mice expressing Crohn's disease-associated ATG16L1 variant (ATG16L1 T300A) were susceptible to colitis induced by dextran sulfate sodium and pathogenic bacteria, respectively(Saitoh et al., 2008; Murthy et al., 2014, 16; Lassen et al., 2014). ATG16L1-deficient macrophages produce high amount of IL-1 $\beta$ and IL-18 in response to lipopolysaccharide (LPS), ATP and monosodium urate (MSU) crystals (Figure 3). Expression of Crohn's disease-associated ATG16L1 variant in peripheral blood mononuclear cells from Crohn's disease patients and in macrophages from genetically engineered mice results in elevated production of IL-1 $\beta$ (Murthy et al., 2014; Lassen et al., 2014; Plantinga et al., 2011). Caspase- 3 and caspase-7, apoptotic proteases, enhance production of IL-1 $\beta$ by inducing proteolytic cleavage of the Crohn's disease-associated ATG16L1 variant(Murthy et al., 2014; Lassen et al., 2014). ATG7-deficient macrophages also produce high amount of $\mathrm{IL}-1 \beta$ and IL-18 in response to various inflammasome inducers(Saitoh et al., 2008). Hence, loss of autophagy in macrophages greatly augments production of IL-1 $\beta$ and IL-18.

\section{Autophagy in inflammasome activation}

NLR family, pyrin domain containing 3 (NLRP3) protein is a well characterized PRR that induces production of IL-1 $\beta$ and IL-18(Latz et al., 2013). Various NLRP3-inflammasome inducers such as ATP, palmitic acid, MSU crystals, silica nanoparticles, cholesterol crystals and influenza $A$ virus cause mitochondrial damage leading to release of reactive oxygen species (ROS). NLRP3 forms the inflammasome complex with ASC and caspase-1, and induces production of IL-1 $\beta$ and IL-18 in response to mitochondrial ROS. Because autophagy maintains cellular homeostasis by promoting turnover of organelles, autophagy-deficiency causes accumulation of old and dysfunctional mitochondria. Accumulated old and dysfunctional mitochondria produce an excess of ROS upon stimulation, thereby potently activating the NLRP3-inflammasome(Zhou et al., 2011; Nakahira et al., 2011, 3) (Figure 3). In addition, lysophagy may also be important for suppression of inflammasome activation, since extracellular irritative particles such as MSU and Silica internalize into cells via the endocytic 
pathway and break lysosomes, which could damage mitochondria. Lysophagy sequesters lysosomes damaged by MSU or Silica in vitro and in vivo(Maejima et al., 2013). Upon influenza $A$ virus infection, nucleotide-binding oligomerization domain containing 2 and its downstream regulator receptor-interacting serine-threonine kinase 2 induce mitophagy by inducing ULK1 phosphorylation to prevent excessive NLRP3-inflammasome activation(Lupfer et al., 2013). Autophagy-deficiency worsens the symptoms of various inflammatory diseases such as colitis, sepsis, pneumonia, diabetes, atherosclerosis, and urinary tract infections by enhancing NLRP3-inflammasome-dependent production of IL-1 $\beta$ and IL-18(Nakahira et al., 2011; Lupfer et al., 2013; Wen et al., 2011; Razani et al., 2012; Wang et al., 2012). On the other hand, inducers of autophagy can suppress inflammasome-dependent production of IL-1 $\beta$ and IL-18, and ameliorate symptoms of inflammation-associated tissue damage(Shaw et al., 2013; Guo et al., 2014; Abderrazak et al., 2015). Hence, autophagy would be an attractive therapeutic target for treatment of inflammasome-related inflammatory diseases.

Autophagy inhibits not only the NLRP3-inflammasome but also other inflammasomes such as the AIM2-inflammasome. Lysine 63-linked ubiquitination of ASC, an essential adaptor molecule of inflammasomes, is induced upon activation of the NLRP3- and AIM2-inflammasomes(Shi et al., 2012). Autophagy recognizes ubiquitinated ASC by the ubiquitin sensor sequestosome 1 (SQSTM1)/p62 and induces selective degradation of inflammasomes thereby suppressing production of IL-1 $\beta$ and IL-18 (Figure 3). Furthermore, the autophagy system delivers IL-1 $\beta$ into lysosomal compartments to induce its degradation(Harris et al., 2011) (Figure 3). Hence, autophagy can target multiple steps of inflammasome activation and thus potently inhibit production of IL-1 $\beta$ and IL-18.

Autophagy limits inflammasome activation under normal and nutrient-rich conditions. However, a recent study has shown that autophagy often mediates the unconventional secretion of IL-1 $\beta$ under nutrient starvation(Dupont et al., 2011). Golgi reassembly stacking protein and $\mathrm{RAB} 8 \mathrm{~A}$, membrane traffic regulators, are involved in autophagy-dependent unconventional secretion of IL-1 $\beta$. On the other hand, other studies have shown that autophagy suppresses IL-1 $\beta$ production under nutrient starvation(Wang et al., 2012; Shi et al., 2012). Hence, a role of autophagy in IL-1 $\beta$ production under nutrient starvation is still unclear and needs to be further investigated.

\section{Autophagy in non-canonical inflammasome activation}

Recent studies have shown that the non-canonical inflammasome consisting of caspase-11 in mouse and caspase- 4 and caspase- 5 in human induces IL- $1 \alpha / \beta$ and IL-18 production in response to cytosolic LPS(Lamkanfi and Dixit, 2014). During infections with gram-negative bacteria, a cluster of guanylate-binding proteins, small interferon-inducible GTPases, moves to the surface of the bacteria-containing vacuoles (BCVs) and induces the membrane rupture(Meunier et al., 2014). Destabilization of BCVs releases bacterial components into the cytosol thereby facilitating the recognition of their LPS by the non-canonical inflammasome. 
Autophagy-deficiency causes accumulation of the destabilized BCVs, resulting in an enhanced activation of the non-canonical inflammasome (Figure 3). Autophagy targets damaged BCVs via ubiquitin and galectin-8, and induces their autophagic degradation as described above. Hence, autophagy-mediated clearance of BCVs prevents excessive induction of the inflammatory response mediated by the non-canonical inflammasome.

\section{Autophagy in calpain-dependent production of $I L-1 \alpha$}

Maturation and production of IL-1 $\alpha$ involve caspase 1-dependent and caspase 1-independent processes(Netea et al., 2014). In caspase-1-independent process, maturation of IL-1 $\alpha$ by calpain is triggered by ROS released from damaged mitochondria. Autophagy-deficiency in phagocytes causes elevated T helper 17 (TH17) cell response, resulting in severe lung tissue damage in a mouse model of tuberculosis(Castillo et al., 2012). Autophagy-deficient macrophages produce high amount of IL-1 $\alpha$ in response to Mycobacterium tuberculosis due to elevated mitochondrial ROS. Hence, mitochondrial ROS play a critical role in activation of the inflammasome and calpain in autophagy-deficient macrophages.

\section{Nucleic acid sensors}

The innate immune system senses viral nucleic acids by PRRs such as Toll-like receptors (TLRs), retinoic acid-inducible gene (RIG)-l-like receptors (RLRs) and cyclic guanosine monophosphate-adenosine monophosphate (cGAMP) synthase (cGAS), and induces production of IFN- $\alpha$ and IFN- $\beta$, type I IFNs(Kawai and Akira, 2010; Yoneyama et al., 2015; Cai et al., 2014). Type I IFNs induce the expression of a series of antiviral factors to establish an antiviral state and play a crucial role in host defense against viruses.

\section{Autophagy in TLR-mediated type / IFN production}

TLR7 and TLR9 sense viral single-stranded RNA (ssRNA) and unmethylated CpG DNA, respectively, in endo-lysosomes and mediate robust production of type I IFNs by plasmacytoid dendritic cells (pDCs)(Kawai and Akira, 2010). Autophagy-deficiency severely impairs TLR7-dependent production of type I IFNs by pDC infected with vesicular stomatitis virus (VSV) and Sendai virus (SeV)(Lee et al., 2007). Autophagy-deficiency also severely impairs TLR9-dependent production of type I IFNs by pDC stimulated with A/D-type unmethylated CpG oligonucleotides (a ligand for TLR9). Furthermore, LAP-deficiency severely impairs DNA-immune complex-induced TLR9-dependent type I IFN production by pDCs(Henault et al., 2012). Hence, autophagy and LAP are required for nucleic acid sensing and TLR-mediated type I IFN production by pDCs.

\section{Autophagy in RLR-mediated type / IFN production}

RIG-I and the melanoma differentiation-associated gene 5 (MDA5), called RLRs, are caspase-recruited domain (CARD)-containing RNA helicases and sense viral 
double-stranded RNA (dsRNA) in the cytosol(Yoneyama et al., 2015). After sensing viral dsRNA, RLRs induce production of type I IFNs through activation of the mitochondrial CARD-containing adaptor protein interferon- $\beta$ promoter stimulator-1 (IPS-1), also called MAVS/VISA/CARDIF. ATG5-deficiency enhances the production of type I IFNs by RNA viruses such as vesicular stomatitis virus (VSV), and inhibits viral replication. ATG5-deficiency causes accumulation of old and dysfunctional mitochondria, which in turn induces elevated expression of IPS-1 protein and generation of mitochondrial ROS, resulting in enhanced production of type I IFNs by dsRNA(Tal et al., 2009). The ATG12-ATG5 conjugates and its binding partner Tu translation elongation factor suppress dsRNA-induced production of type I IFNs by disrupting signals from RLRs and IPS-1(Jounai et al., 2007; Lei et al., 2012). Hence, autophagy and a unique function of autophagy-related proteins are involved in negative regulation of RLR-mediated type I IFN production.

\section{Autophagy in cGAS-mediated type / IFN production}

Recent studies have identified that cGAS senses microbial dsDNA in the cytosol(Cai et al., 2014). After dsDNA recognition, cGAS generates cGAMP to activate the stimulator of interferon genes (STING), a downstream regulator, which in turn induces production of type I IFNs, resulting in the establishment of an antiviral state. Loss of ATG9A causes hyper aggregation of STING on Golgi-derived compartments and enhances STING-dependent production of type I IFNs(Saitoh et al., 2009). ATG9A controls subcellular localization of STING via unknown mechanisms. ULK1 inhibition also enhances STING-dependent production of type I IFNs(Konno et al., 2013). ULK1 induces phosphorylation of STING to prevent sustained type I IFN production. Inhibition of Beclin1 enhances cGAS-dependent production of type I IFNs. Beclin1 binds with cGAS to inhibit cGAMP synthesis(Liang et al., 2014). Hence, unique functions of autophagy-related proteins limit production of type I IFNs induced by cytosolic dsDNA.

\section{Endogenous antigen processing for MHC class // presentation}

In contrast to innate immune sensing via PRRs, the adaptive immune system relies on the recognition of peptides processed from pathogen- or tumor-associated proteins and their presentation on major histocompatibility complex (MHC) molecules. For this purpose, $\mathrm{MHC}$ class I molecules get primarily loaded with proteasomal products for $\mathrm{CD}^{+} \mathrm{T}$ cell recognition, while $\mathrm{MHC}$ class II molecules receive fragments of lysosomal degradation for $\mathrm{CD4}^{+} \mathrm{T}$ cell recognition(Blum et al., 2013). Autophagy delivers cytoplasmic constituents for lysosomal hydrolysis, thereby contributing to endogenous antigen processing for MHC class II presentation (Figure 4)(Romao et al., 2013a). This was first noted for a prominent CD4 ${ }^{+} \mathrm{T}$ cell antigen of the Epstein Barr virus (EBV)(Paludan et al., 2005; Leung et al., 2010). Further studies demonstrated that rapamycin-induced autophagy or targeting model antigens to 
autophagosomes by fusion to LC3 augments intracellular antigen presentation on MHC class II molecules(Jagannath et al., 2009; Schmid et al., 2007; Jin et al., 2014). However, the best characterized physiological process that requires intracellular antigen loading is $T$ cell education in the thymus(Nedjic et al., 2008). Thymic epithelial cells (TECs) present self-antigens on MHC molecules for the induction of central T cell tolerance. Indeed, TECs display high constitutively active levels of autophagy(Nedjic et al., 2008; Kasai et al., 2009), resulting in compromised $\mathrm{CD}^{+}{ }^{+} \mathrm{T}$ cell education without it(Nedjic et al., 2008). Antigen targeting to the autophagy machinery depletes specific $\mathrm{T}$ cells during negative selection, which eliminates autoreactive T cells(Aichinger et al., 2013). Therefore, endogenous MHC class II antigen processing via autophagy contributes to the induction of $T$ cell tolerance and promotes the presentation of intracellular antigens to $\mathrm{CD} 4^{+} \mathrm{T}$ cells.

\section{Exogenous antigen processing for MHC class // presentation}

In addition to this function of classical autophagy in antigen processing, the LC3 lipidation machinery also regulates exogenous antigen processing via phagocytosis. During this LC3-associated phagocytosis (LAP), LC3 is found coupled to a subset of phagosomal membranes that surround TLR2, T cell immunoglobulin mucin protein 4 (TIM4), Fc receptor and Dectin-1 binding cargo(Sanjuan et al., 2007; Martinez et al., 2011; Florey et al., 2011; Romao et al., 2013b; Ma et al., 2012). Production of reactive oxygen species seems to be required to maintain LC3 conjugation to LAP phagosomes(Romao et al., 2013b)(Martinez et al., 2015). The fate of these LAP phagosomes depends on the cellular background, in which they form. Mouse macrophages were found to rapidly degrade LAP phagosome content in lysosomes, possibly by LC3B dependent recruitment of the FYVE and coiled-coil domain containing protein 1 (FYCO1), which might accelerate microtubule transport of LAP phagosomes(Sanjuan et al., 2007; Martinez et al., 2011; Ma et al., 2014, 1)(Ma et al., 2014; Martinez et al., 2011; Sanjuan et al., 2007). In contrast, plasmacytoid dendritic cells (DCs), human macrophages as well as monocyte-derived DCs seem to stabilize these vesicles for the fusion with TLR containing endosomes and prolonged antigen processing for MHC class II presentation, respectively(Romao et al., 2013b; Henault et al., 2012)(Henault et al., 2012; Romao et al., 2013). Both, Dectin-1 and TLR2 engaging cargo seem to be efficiently processed via LAP for MHC class II presentation (Figure 4)(Romao et al., 2013b; Ma et al., 2012)(Ma et al., 2012; Romao et al., 2013). Similarly, the LC3 lipidation machinery appears to be required for efficient MHC class II presentation in vivo(Lee et al., 2010). Moreover, hydrolases that facilitate antigen processing can be transported into lysosomes via autophagy, as shown for peptidylarginine deiminases (PADs) that generate citrullinated peptides, which constitute $\mathrm{CD}^{+} \mathrm{T}$ cell epitopes in rheumatoid arthritis(Ireland and Unanue, 2011). LAP. however, does not seem to affect all phagocytosed cargo similarly. While the autophagy machinery has been reported to assist the transport of B cell receptor recognized antigens to TLR containing endosomes(Chaturvedi et al., 2008), this does not seem to be significantly 
required to establish antigen presentation to helper $T$ cells during germinal center reactions(Pengo et al., 2013). Thus, the autophagy machinery that mediates LC3 lipidation can modify phagosome fate and content, facilitating exogenous antigen presentation onto MHC class II molecules.

\section{Antigen processing for MHC class / presentation}

The classical function of the LC3 lipidation machinery, delivering substrates for lysosomal degradation, might limit antigen access to proteasomal turn-over(Wenger et al., 2012). In addition, proteasomes can be targeted by the autophagy machinery(Kristensen et al., 2008)(Cuervo et al., 1995), but this might mainly affect dysfunctional proteasomes(Marshall et al., 2015) and contribute little to further constrain proteasomal antigen processing for $\mathrm{MHC}$ class I presentation(Wenger et al., 2012). However, viral infections can block this proteasomal degradation and transporter associated with antigen processing (TAP) mediated import of antigenic peptides into the endoplasmic reticulum (ER) for $\mathrm{MHC}$ class I loading. Under these conditions, autophagy and possibly even LAP might contribute to MHC class I loading (Figure 4). Indeed, involvement of autophagy in MHC class I antigen presentation during herpesvirus infection in vitro was shown for herpes simplex virus (HSV) and human cytomegalovirus (HCMV), both encoding TAP blocking proteins(English et al., 2009; Tey and Khanna, 2012)(English et al., 2009; Tey and Khanna, 2012). Notably, autophagy was reported to assist in interferon- $\gamma$ (IFN- $\gamma$ ) mediated MHC class I up-regulation(Li et al., 2010). Autophagy therefore might contribute to the delivery of intracellular antigens to vesicular $\mathrm{MHC}$ class I loading compartments, and to extracellular antigen processing for MHC class I presentation, so called cross-presentation. Cross-presentation of respiratory syncytial virus (RSV), HIV, Chlamydia and Aspergillus antigens were reported to benefit from the LC3 lipidation machinery(Johnstone et al., 2012; Blanchet et al., 2010; Fiegl et al., 2013; De Luca et al., 2012), presumably via LAP phagosome fusion with vesicular MHC class I loading compartments. Hence, vesicular MHC class I loading might benefit from autophagy and LAP, especially when TAP is blocked.

\section{Antigen packaging for cross-presentation}

In addition to the catabolic functions of the LC3 lipidation machinery, alterations affecting the completion of the autophagosome maturation process might promote exocytosis. This has been demonstrated in yeast for signal peptide independent secretion(Duran et al., 2010; Manjithaya et al., 2010)(Duran et al., 2010; Manjithaya et al., 2010) and suggested among others for high mobility group protein B1 (HMGB1), IL-1 $\beta$, ATP and secretory lysosome release by mammalian cells(Thorburn et al., 2009; Dupont et al., 2011; Martins et al., 2014; DeSelm et al., 2011). Moreover, some viruses like HIV, polio and EBV might utilize exocytosis involving autophagic membranes to exit infected cells(Kyei et al., 2009; Jackson et al., 2005; Nowag et al., 2014). This autophagic exocytosis could also benefit antigen processing and 
has been shown to facilitate tumor and influenza $A$ virus antigen cross-presentation (Figure 4)(Uhl et al., 2009; Li et al., 2008)(Li et al., 2008; Uhl et al., 2009). Accordingly, vesicular fractions generated from antigen donor cells under autophagy stimulating and lysosome inhibiting conditions, some of them called defective ribosomal products in blebs (dribbles), are now being explored as antigen formulations for better cross-presentation(Ye et al., 2014). Thus, autophagic membranes might contribute to antigen release for efficient cross-presentation.

\section{Autophagy in T cell development}

Beside its role in antigen processing, autophagy shapes adaptive immunity throughout lymphocyte development and effector functions. While myeloid cells seem to differentiate in the absence of autophagy and can even cause severe myeloproliferation, autophagy deficiency in hematopoietic progenitor cells of mice severely compromises the lymphoid lineage(Mortensen et al., 2011, 7). Accordingly, thymocyte development up-regulates and is dependent on functional autophagy(Pua et al., 2007; Arsov et al., 2011)(Arsov et al., 2011; Pua et al., 2007). In the absence of autophagic clearance of damaged mitochondria (so called mitophagy) naïve T cell numbers are severely reduced(Pua et al., 2009; Farfariello et al., 2012)(Farfariello et al., 2012; Pua et al., 2009). Thus, mitophagy seems to be a prerequisite for $\mathrm{T}$ cell development.

\section{Autophagy in T cell function}

Proliferative T cell responses up-regulated autophagy(Pua et al., 2007), on which T cell survival during proliferation depends(Pua et al., 2007; Willinger and Flavell, 2012). Lack of autophagy leads to terminally differentiated $\mathrm{CD}^{+} \mathrm{T}$ cells in senescence with dysfunctional mitochondria, increased ROS production and elevated p38 MAPK levels(Henson et al., 2014). Indeed, p38 MAPK suppresses autophagy in these cells, and its inhibition restores proliferative function. Furthermore, the altered cell organelle homeostasis with increased ER structures compromises $\mathrm{Ca}^{2+}$ mobilization after T cell stimulation(Jia et al., 2011). This seems not only to affect effector, but also regulatory T cells(Parekh et al., 2013). Moreover, CD4 ${ }^{+} T$ cells defective in autophagy are susceptible to apoptosis upon activation(Kovacs et al., 2012). In addition, autophagy deficiency caused impaired memory $\mathrm{CD}^{+} \mathrm{T}$ cell survival during lymphocytic choriomeningitis virus (LCMV), influenza virus and mouse cytomegalovirus (MCMV) infection(Puleston et al., 2014; Xu et al., 2014). T cell memory responses could be partially restored with the autophagy stimulator spermidine(Puleston et al., 2014). Therefore, autophagy might be required for lymphocyte expansion and memory maintenance.

\section{Autophagy in B cell development}

The loss of autophagy in developing $B$ cells results in marginally decreased total numbers (Arsov et al., 2011; Miller et al., 2008)(Arsov et al., 2011; Miller et al., 2008). However, murine 
B1a cells are compromised after essential autophagy gene deficiency(Miller et al., 2008; Pengo et al., 2013)(Miller et al., 2008; Pengo et al., 2013). This decrease seems to originate from autophagy dependent pre- to pro-B cell transition. Therefore, a subset of B cells is dependent on autophagy during their differentiation.

\section{Autophagy in plasma cell and memory B cell maintenance}

In line with the dependency of functional autophagy for B cell development, effector functions of the humoral immune response are also affected by autophagy deficiency. The terminal effector function resides in plasma cells that continuously generate antibodies. In addition, memory $\mathrm{B}$ cells can be reactivated for antibody production upon cognate antigen encounter. Both, $T$ cell dependent and independent antibody responses that lead to plasma cell differentiation require autophagy(Pengo et al., 2013; Conway et al., 2013a)(Conway et al., 2013; Pengo et al., 2013). Moreover, long-term survival of plasma cells in the bone marrow of mice is reduced by autophagy deficiency(Pengo et al., 2013). The absence of autophagy in plasma cells results in a massive enlargement of the ER, which triggers unfolded protein responses during the production of immunoglobulins. This uncontrolled stress response is thought to induce cell death(Pengo et al., 2013). However, a direct effect of autophagy on antibody production by plasma and multiple myeloma cells could not been shown(Milan et al., 2015; Pengo et al., 2013). In addition to this role in plasma cell maintenance, autophagy is also required in memory $B$ cell survival. Mice with autophagy-deficient $B$ cells were severely impaired in their specific secondary antibody responses towards influenza $A$ virus due to compromised memory B cell maintenance(Chen et al., 2014). Consequently, humoral immune responses, particularly the protection due to sustained antibody production and secondary responses, necessitate autophagy.

\section{Concluding remarks}

Since the discovery of Atg proteins, the molecular mechanism of autophagy and its relationship with immunity has been extensively investigated. As described in this review, it is now indisputable that autophagy and its machinery play various and critical roles in immunity, including the elimination of pathogens, the regulation of inflammation responses, antigen processing/presentation, and development of immune cells. However, we are still in the process of understanding the exact functions of Atg proteins and mechanism of autophagosome formation. Future investigation will clarify the fundamental mechanism of autophagy in more detail and will reveal unidentified roles of autophagy in immunity.

\section{Acknowledgements}

We apologize to authors whose relevant publications could not be introduced in this review 
due to space limitations. S.T.S., T.S., and Y.T. are supported by the Ministry of Education, Culture, Sports, Science and Technology (MEXT) of Japan and by Japan Science and Technology Agency CREST. H.N. and C.M. are supported by Cancer Research Switzerland (KFS-3234-08-2013), Worldwide Cancer Research (14-1033), KFSP ${ }^{\mathrm{MS}}$ and KFSP ${ }^{\mathrm{HHLD}}$ of the University of Zurich, the Baugarten Foundation, the Sobek Foundation, Fondation Acteria, the Swiss Vaccine Research Institute and the Swiss National Science Foundation (310030_143979 and CRSII3_136241). 


\section{Box 1: In vivo roles of autophagy in pathogen infection}

In mice, the conditional knockout of Atg genes was employed for these studies since the systemic knockout of Atg genes results in lethality shortly after birth(Mizushima and Komatsu, 2011). For example, Atg5 knockout in myeloid cells resulted in decreased resistance to Listeria monocytogenes and Toxoplasma gondii(Zhao et al., 2008, 5) and Mycobacterium tuberculosis(Watson et al., 2012; Castillo et al., 2012). Atg5 or Atg16L1 knockout in intestinal epithelial cells also resulted in decreased resistance to Salmonella enterica serotype Typhimurium (S. Typhimurium)(Benjamin et al., 2013; Conway et al., 2013b). Survival of neonatal mice after Sindbis virus infection was decreased by neuron-specific knockout of Atg5(Orvedahl et al., 2010). Atg5 knockout in dendritic cells in mice decreased survival after herpes simplex virus type 2 (HSV-2)(Lee et al., 2010). In Drosophila, the knockdown of Atg proteins decreased host survival after Listeria monocytogenes infection(Yano et al., 2008). Autophagy suppresses vesicular stomatitis virus (VSV) replication in Drosophila(Shelly et al., 2009). Caenorhabditis elegans treated with feeding RNAi for atg genes as well as Dictyostelium mutants of atg genes showed reduced survival after Salmonella Typhimurium infection(Jia et al., 2009).

In contrast, however, systemic Atg16L1 hypomorphic mice, which show abnormality in the packaging and secretion of antimicrobial granules in Paneth cells(Cadwell et al., 2008, 2010), exhibit enhanced resistance to urinary tract infection of uropathogenic Escherichia coli (UPEC) and intestinal infection by Citrobacter rodentium with increased inflammatory cytokine response and the increased recruitment of monocytes and neutrophils to infected sites(Wang et al., 2012; Marchiando et al., 2013). The enhanced clearance of bacteria in systemic Atg16L1 hypomorphic mice may be partly explained by the enhanced inflammatory responses seen in autophagy-deficient macrophages(Saitoh et al., 2008).

\section{Box 2: Immune signals that regulate autophagy}

TLR4 stimulation by lipopolysaccharides (LPS) induces autophagosomes in macrophages(Xu et al., 2007). Other TLR ligands also induce GFP-LC3 dots and autolysosomes in macrophages(Delgado et al., 2008). Nod1 and 2, which are cytosolic receptors for bacterial peptidoglycan, interact with Atg16L1 and mediate the recruitment of Atg16L1 to the bacterial entry site in non-phagocytic cells, macrophages, and lymphocytes(Travassos et al., 2010). Nod2 stimulation also induces autophagosomes in dendritic cells(Cooney et al., 2010). NLRX1 is required for VSV-induced autophagy by interacting with Atg16L1 complex through TUFM(Lei et al., 2012). In contrast, other Nod-like receptors, including NLRC4, NLRP3, NLRP4, and NLRP10 suppress autophagy by sequestering Beclin 1(Jounai et al., 2011). HMGB1, which is released into the extracellular space and activates TLRs, is required for autophagy and suppression of endotoxin-induced cell death of macrophages(Yanai et al., 2013). HMGB1 has also been shown to bind to Beclin 1 and induces autophagy by releasing 
Beclin 1 from Bcl-2(Tang et al., 2010). HIV-1 envelope glycoproteins (Env) expressed at the cell surface activate autophagy and causes apoptosis in bystander CD4 ${ }^{+} \mathrm{T}$ cells through the chemokine receptor CXCR4(Espert et al., 2006). IFN-y has been shown to induce autophagy in macrophages in an Irgm1-dependent manner(Gutierrez et al., 2004; Singh et al., 2006). TNF- $\alpha$ induces autophagy in myoblasts in an NF-KB-independent manner(Keller et al., 2011), and enhances NDP52 recruitment to Shigella in HeLa cells(Mostowy et al., 2011). IL-1 $\beta$ also induces autophagy in macrophages in a TBK-1-dependent manner (Pilli et al., 2012). In contrast, T Helper 2 cytokines IL-4 and IL-13 suppress autophagy(Harris et al., 2007). The transcription factor STAT3, which is activated by various cytokines, has been shown to suppress autophagy through inhibition of protein kinase $\mathrm{R}$ (Shen et al., 2012). 


\section{Figure legends}

\section{Figure 1: A schematic diagram of autophagy}

Autophagy-inducing signals (e.g. amino acid starvation and pathogen infection) initiate the formation of the isolation membrane (also called the phagophore). The closure of the isolation membrane results in the formation of the autophagosome. The following lysosome-autophagosome fusion leads to the degradation of the contents inside the autophagosome by lysosomal hydrolases in the autolysosome.

\section{Figure 2: Xenophagy and LC3-associated phagocytosis (LAP)}

(left) In ubiquitin-dependent xenophagy, the recruitment of Atg proteins occurs after the pathogen-containing endosome is ruptured. Endosomal membrane proteins are ubiquitinated immediately after the membrane rupture. In addition, adaptor proteins such as p62, NDP52, and optineurin mediate recruitment of LC3 to ubiquitinated substrate. NDP52 can be recruited to the ruptured endosomal membrane through the binding to galectin-8, which recognizes $\beta$-galactose chains in the lumen of endosomes (not depicted here). Isolation membrane formation takes place in the proximity of the pathogen-containing endosome, and finally the autophagosome engulfs the pathogen-containing endosome. The following lysosome-autophagosome fusion eliminates the pathogen.

(right) In contrast to xenophagy, the double membrane autophagosome is not formed in LAP. Instead, the phagosomal membrane is directly decorated by LC3 lipidation. LAP facilitates lysosome-phagosome fusion or prolonged antigen processing for $\mathrm{MHC}$ class II presentation in a cell type specific manner as discussed in the adaptive immunity section.

\section{Figure 3: Autophagy suppresses inflammasome-mediated production of IL-1 $\beta$}

NLRP3 forms an inflammasome with its adaptor ASC, and its excessive activation causes inflammatory diseases such as gout. Activators of the NLRP3 inflammasome cause mitochondrial damage, which in turn causes production of reactive oxygen species (ROS), resulting in activation of the NLRP3-inflammasome. Autophagy induces elimination of old and dysfunctional mitochondria to suppress ROS generation and subsequent activation of the NLRP3-inflammasome. Autophagy also induces elimination of damaged phagosomes, ubiquitinated ASC and IL-1 $\beta$ to suppress IL-1 $\beta$ production mediated by other inflammasomes.

\section{Figure 4: Autophagy proteins in MHC restricted antigen presentation}

Autophagy proteins contribute at least by three pathways to vesicular antigen loading onto MHC molecules. Autophagosomes can fuse with endosomal MHC loading compartments and deliver cytoplasmic constituents for MHC class II loading. MHC class I loading might also occur in these vesicular compartments, especially under conditions, in which the classical MHC class I antigen processing, for example TAP, is inhibited. LC3 associated 
phagocytosis (LAP) can deliver extracellular antigens to this loading compartment. LC3 might need to be deconjugated from the outer autophagosomal and the LAP phagosome membrane by Atg 4 for efficient fusion with the endosomal MHC loading compartment. Finally, signal peptide independent, but autophagy dependent exocytosis seems to efficiently transfer antigens from donor cells to antigen presenting cells (APCs), primarily for cross-presentation onto MHC class I molecules. 


\section{References}

Abderrazak, A., D. Couchie, D.F.D. Mahmood, R. El Hage, C. Vindis, M. Laffargue, V. Matéo, B. Büchele, M. Rubio Ayala, M. El Gaafary, T. Syrovets, M.-N. Slimane, B. Friguet, T. Fulop, T. Simmet, K. El Hadri, and M. Rouis. 2015. Anti-Inflammatory and Anti-Atherogenic Effects of the Inflammasome NLRP3 Inhibitor, Arglabin, in ApoE2.Ki Mice Fed a High Fat Diet. Circulation. doi:10.1161/CIRCULATIONAHA.114.013730.

Aichinger, M., C. Wu, J. Nedjic, and L. Klein. 2013. Macroautophagy substrates are loaded onto $\mathrm{MHC}$ class II of medullary thymic epithelial cells for central tolerance. J. Exp. Med. 210:287-300. doi:10.1084/jem.20122149.

Arsov, I., A. Adebayo, M. Kucerova-Levisohn, J. Haye, M. MacNeil, F.N. Papavasiliou, Z. Yue, and B.D. Ortiz. 2011. A role for autophagic protein beclin 1 early in lymphocyte development. J. Immunol. Baltim. Md 1950. 186:2201-2209. doi:10.4049/jimmunol.1002223.

Benjamin, J.L., R. Sumpter Jr, B. Levine, and L.V. Hooper. 2013. Intestinal Epithelial Autophagy Is Essential for Host Defense against Invasive Bacteria. Cell Host Microbe. 13:723-734. doi:10.1016/j.chom.2013.05.004.

Birmingham, C.L., A.C. Smith, M.A. Bakowski, T. Yoshimori, and J.H. Brumell. 2006. Autophagy controls Salmonella infection in response to damage to the Salmonella-containing vacuole. J. Biol. Chem. 281:11374-11383. doi:10.1074/jbc.M509157200.

Blanchet, F.P., A. Moris, D.S. Nikolic, M. Lehmann, S. Cardinaud, R. Stalder, E. Garcia, C. Dinkins, F. Leuba, L. Wu, O. Schwartz, V. Deretic, and V. Piguet. 2010. Human Immunodeficiency Virus-1 Inhibition of Immunoamphisomes in Dendritic Cells Impairs Early Innate and Adaptive Immune Responses. Immunity. 32:654-669. doi:10.1016/j.immuni.2010.04.011.

Blum, J.S., P.A. Wearsch, and P. Cresswell. 2013. Pathways of Antigen Processing. Annu. Rev. Immunol. 31:443-473. doi:10.1146/annurev-immunol-032712-095910.

Cadwell, K., J.Y. Liu, S.L. Brown, H. Miyoshi, J. Loh, J.K. Lennerz, C. Kishi, W. Kc, J.A. Carrero, S. Hunt, C.D. Stone, E.M. Brunt, R.J. Xavier, B.P. Sleckman, E. Li, N. Mizushima, T.S. Stappenbeck, and H.W. Virgin 4th. 2008. A key role for autophagy and the autophagy gene Atg16l1 in mouse and human intestinal Paneth cells. Nature. 456:259-263. doi:10.1038/nature07416.

Cadwell, K., K.K. Patel, N.S. Maloney, T.-C. Liu, A.C.Y. Ng, C.E. Storer, R.D. Head, R. Xavier, T.S. Stappenbeck, and H.W. Virgin. 2010. Virus-plus-susceptibility gene interaction determines Crohn's disease gene Atg16L1 phenotypes in intestine. Cell. 141:1135-1145. doi:10.1016/j.cell.2010.05.009.

Cai, X., Y.-H. Chiu, and Z.J. Chen. 2014. The cGAS-cGAMP-STING pathway of cytosolic DNA sensing and signaling. Mol. Cell. 54:289-296. doi:10.1016/j.molcel.2014.03.040.

Castillo, E.F., A. Dekonenko, J. Arko-Mensah, M.A. Mandell, N. Dupont, S. Jiang, M. Delgado-Vargas, G.S. Timmins, D. Bhattacharya, H. Yang, J. Hutt, C.R. Lyons, K.M. Dobos, and V. Deretic. 2012. Autophagy protects against active tuberculosis by suppressing bacterial burden and inflammation. Proc. Natl. Acad. Sci. U. S. A. 109:E3168-3176. doi:10.1073/pnas.1210500109.

Chaturvedi, A., Dorward, D., and Pierce, S.K. (2008). The B cell receptor governs the subcellular location of Toll-like receptor 9 leading to hyperresponses to 
DNA-containing antigens. Immunity 28, 799-809.

Chen, M., M.J. Hong, H. Sun, L. Wang, X. Shi, B.E. Gilbert, D.B. Corry, F. Kheradmand, and J. Wang. 2014. Essential role for autophagy in the maintenance of immunological memory against influenza infection. Nat. Med. 20:503-510. doi:10.1038/nm.3521.

Clark, S.L., Jr. 1957. Cellular differentiation in the kidneys of newborn mice studies with the electron microscope. J. Biophys. Biochem. Cytol. 3:349-362.

Conway, K.L., P. Kuballa, B. Khor, M. Zhang, H.N. Shi, H.W. Virgin, and R.J. Xavier. 2013a. ATG5 regulates plasma cell differentiation. Autophagy. 9:528-537. doi:10.4161/auto.23484.

Conway, K.L., P. Kuballa, J.-H. Song, K.K. Patel, A.B. Castoreno, O.H. Yilmaz, H.B. Jijon, M. Zhang, L.N. Aldrich, E.J. Villablanca, J.M. Peloquin, G. Goel, I.-A. Lee, E. Mizoguchi, H.N. Shi, A.K. Bhan, S.Y. Shaw, S.L. Schreiber, H.W. Virgin, A.F. Shamji, T.S. Stappenbeck, H.-C. Reinecker, and R.J. Xavier. 2013b. Atg16l1 is required for autophagy in intestinal epithelial cells and protection of mice from Salmonella infection. Gastroenterology. 145:1347-1357. doi:10.1053/j.gastro.2013.08.035.

Cooney, R., J. Baker, O. Brain, B. Danis, T. Pichulik, P. Allan, D.J.P. Ferguson, B.J. Campbell, D. Jewell, and A. Simmons. 2010. NOD2 stimulation induces autophagy in dendritic cells influencing bacterial handling and antigen presentation. Nat. Med. 16:90-97. doi:10.1038/nm.2069.

Cossart, P., and P.J. Sansonetti. 2004. Bacterial invasion: the paradigms of enteroinvasive pathogens. Science. 304:242-248. doi:10.1126/science.1090124.

Cuervo, A.M., Palmer, A., Rivett, A.J., and Knecht, E. (1995). Degradation of proteasomes by lysosomes in rat liver. Eur J Biochem 227, 792-800.

Delgado, M.A., R.A. Elmaoued, A.S. Davis, G. Kyei, and V. Deretic. 2008. Toll-like receptors control autophagy. EMBO J. 27:1110-1121. doi:10.1038/emboj.2008.31.

Deretic, V., T. Saitoh, and S. Akira. 2013. Autophagy in infection, inflammation and immunity. Nat. Rev. Immunol. 13:722-737. doi:10.1038/nri3532.

DeSelm, C.J., B.C. Miller, W. Zou, W.L. Beatty, E. van Meel, Y. Takahata, J. Klumperman, S.A. Tooze, S.L. Teitelbaum, and H.W. Virgin. 2011. Autophagy proteins regulate the secretory component of osteoclastic bone resorption. Dev. Cell. 21:966-974. doi:10.1016/j.devcel.2011.08.016.

Dooley, H.C., M. Razi, H.E.J. Polson, S.E. Girardin, M.I. Wilson, and S.A. Tooze. 2014. WIPI2 links LC3 conjugation with PI3P, autophagosome formation, and pathogen clearance by recruiting Atg12-5-16L1. Mol. Cell. 55:238-252. doi:10.1016/j.molcel.2014.05.021.

Dreux, M., and F.V. Chisari. 2010. Viruses and the autophagy machinery. Cell Cycle. 9:1295-1307. doi:10.4161/cc.9.7.11109.

Dupont, N., S. Jiang, M. Pilli, W. Ornatowski, D. Bhattacharya, and V. Deretic. 2011. Autophagy-based unconventional secretory pathway for extracellular delivery of IL-1ß. EMBO J. 30:4701-4711. doi:10.1038/emboj.2011.398.

Dupont, N., S. Lacas-Gervais, J. Bertout, I. Paz, B. Freche, G.T. Van Nhieu, F.G. van der Goot, P.J. Sansonetti, and F. Lafont. 2009. Shigella phagocytic vacuolar membrane remnants participate in the cellular response to pathogen invasion and are regulated 
by autophagy. Cell Host Microbe. 6:137-149. doi:10.1016/j.chom.2009.07.005.

Duran, J.M., C. Anjard, C. Stefan, W.F. Loomis, and V. Malhotra. 2010. Unconventional secretion of Acb1 is mediated by autophagosomes. J. Cell Biol. 188:527-536. doi:10.1083/jcb.200911154.

English, L., M. Chemali, J. Duron, C. Rondeau, A. Laplante, D. Gingras, D. Alexander, D. Leib, C. Norbury, R. Lippé, and M. Desjardins. 2009. Autophagy enhances the presentation of endogenous viral antigens on MHC class I molecules during HSV-1 infection. Nat. Immunol. 10:480-487. doi:10.1038/ni.1720.

Espert, L., M. Denizot, M. Grimaldi, V. Robert-Hebmann, B. Gay, M. Varbanov, P. Codogno, and M. Biard-Piechaczyk. 2006. Autophagy is involved in T cell death after binding of HIV-1 envelope proteins to CXCR4. J. Clin. Invest. 116:2161-2172. doi:10.1172/JCl26185.

Farfariello, V., C. Amantini, and G. Santoni. 2012. Transient receptor potential vanilloid 1 activation induces autophagy in thymocytes through ROS-regulated AMPK and Atg4C pathways. J. Leukoc. Biol. 92:421-431. doi:10.1189/jlb.0312123.

Fiegl, D., D. Kägebein, E.M. Liebler-Tenorio, T. Weisser, M. Sens, M. Gutjahr, and M.R. Knittler. 2013. Amphisomal route of MHC class I cross-presentation in bacteria-infected dendritic cells. J. Immunol. Baltim. Md 1950. 190:2791-2806. doi:10.4049/jimmunol.1202741.

Flannagan, R.S., G. Cosío, and S. Grinstein. 2009. Antimicrobial mechanisms of phagocytes and bacterial evasion strategies. Nat. Rev. Microbiol. 7:355-366. doi:10.1038/nrmicro2128.

Florey, O., S.E. Kim, C.P. Sandoval, C.M. Haynes, and M. Overholtzer. 2011. Autophagy machinery mediates macroendocytic processing and entotic cell death by targeting single membranes. Nat. Cell Biol. 13:1335-1343. doi:10.1038/ncb2363.

Fujita, N., M. Hayashi-Nishino, H. Fukumoto, H. Omori, A. Yamamoto, T. Noda, and T. Yoshimori. 2008a. An Atg4B mutant hampers the lipidation of LC3 paralogues and causes defects in autophagosome closure. Mol. Biol. Cell. 19:4651-4659. doi:10.1091/mbc.E08-03-0312.

Fujita, N., T. Itoh, H. Omori, M. Fukuda, T. Noda, and T. Yoshimori. 2008b. The Atg16L complex specifies the site of LC3 lipidation for membrane biogenesis in autophagy. Mol. Biol. Cell. 19:2092-2100. doi:10.1091/mbc.E07-12-1257.

Fujita, N., E. Morita, T. Itoh, A. Tanaka, M. Nakaoka, Y. Osada, T. Umemoto, T. Saitoh, H. Nakatogawa, S. Kobayashi, T. Haraguchi, J.-L. Guan, K. Iwai, F. Tokunaga, K. Saito, K. Ishibashi, S. Akira, M. Fukuda, T. Noda, and T. Yoshimori. 2013. Recruitment of the autophagic machinery to endosomes during infection is mediated by ubiquitin. J. Cell Biol. 203:115-128. doi:10.1083/jcb.201304188.

Fujita, N., T. Saitoh, S. Kageyama, S. Akira, T. Noda, and T. Yoshimori. 2009. Differential involvement of Atg16L1 in Crohn disease and canonical autophagy: analysis of the organization of the Atg16L1 complex in fibroblasts. J. Biol. Chem. 284:32602-32609. doi:10.1074/jbc.M109.037671.

Fujita, N., and T. Yoshimori. 2011. Ubiquitination-mediated autophagy against invading bacteria. Curr. Opin. Cell Biol. 23:492-497. doi:10.1016/j.ceb.2011.03.003.

Guo, W., Y. Sun, W. Liu, X. Wu, L. Guo, P. Cai, X. Wu, X. Wu, Y. Shen, Y. Shu, Y. Gu, and Q. Xu. 2014. Small molecule-driven mitophagy-mediated NLRP3 inflammasome 
inhibition is responsible for the prevention of colitis-associated cancer. Autophagy. 10:972-985. doi:10.4161/auto.28374.

Gutierrez, M.G., S.S. Master, S.B. Singh, G.A. Taylor, M.I. Colombo, and V. Deretic. 2004. Autophagy is a defense mechanism inhibiting BCG and Mycobacterium tuberculosis survival in infected macrophages. Cell. 119:753-766. doi:10.1016/j.cell.2004.11.038.

Hamasaki, M., N. Furuta, A. Matsuda, A. Nezu, A. Yamamoto, N. Fujita, H. Oomori, T. Noda, T. Haraguchi, Y. Hiraoka, A. Amano, and T. Yoshimori. 2013. Autophagosomes form at ER-mitochondria contact sites. Nature. 495:389-393. doi:10.1038/nature11910.

Hampe, J., A. Franke, P. Rosenstiel, A. Till, M. Teuber, K. Huse, M. Albrecht, G. Mayr, F.M. De La Vega, J. Briggs, S. Günther, N.J. Prescott, C.M. Onnie, R. Häsler, B. Sipos, U.R. Fölsch, T. Lengauer, M. Platzer, C.G. Mathew, M. Krawczak, and S. Schreiber. 2007. A genome-wide association scan of nonsynonymous SNPs identifies a susceptibility variant for Crohn disease in ATG16L1. Nat. Genet. 39:207-211. doi:10.1038/ng1954.

Harris, J., S.A. De Haro, S.S. Master, J. Keane, E.A. Roberts, M. Delgado, and V. Deretic. 2007. T Helper 2 Cytokines Inhibit Autophagic Control of Intracellular Mycobacterium tuberculosis. Immunity. 27:505-517. doi:10.1016/j.immuni.2007.07.022.

Harris, J., M. Hartman, C. Roche, S.G. Zeng, A. O'Shea, F.A. Sharp, E.M. Lambe, E.M. Creagh, D.T. Golenbock, J. Tschopp, H. Kornfeld, K.A. Fitzgerald, and E.C. Lavelle. 2011. Autophagy controls IL-1beta secretion by targeting pro-IL-1beta for degradation. J. Biol. Chem. 286:9587-9597. doi:10.1074/jbc.M110.202911.

Henault, J., J. Martinez, J.M. Riggs, J. Tian, P. Mehta, L. Clarke, M. Sasai, E. Latz, M.M. Brinkmann, A. Iwasaki, A.J. Coyle, R. Kolbeck, D.R. Green, and M.A. Sanjuan. 2012. Noncanonical autophagy is required for type I interferon secretion in response to DNA-immune complexes. Immunity. 37:986-997. doi:10.1016/j.immuni.2012.09.014.

Henson, S.M., A. Lanna, N.E. Riddell, O. Franzese, R. Macaulay, S.J. Griffiths, D.J. Puleston, A.S. Watson, A.K. Simon, S.A. Tooze, and A.N. Akbar. 2014. p38 signaling inhibits mTORC1-independent autophagy in senescent human CD8 ${ }^{+} \mathrm{T}$ cells. J. Clin. Invest. 124:4004-4016. doi:10.1172/JCl75051.

Huang, J., and J.H. Brumell. 2014. Bacteria-autophagy interplay: a battle for survival. Nat. Rev. Microbiol. 12:101-114. doi:10.1038/nrmicro3160.

Huett, A., R.J. Heath, J. Begun, S.O. Sassi, L.A. Baxt, J.M. Vyas, M.B. Goldberg, and R.J. Xavier. 2012. The LRR and RING Domain Protein LRSAM1 Is an E3 Ligase Crucial for Ubiquitin-Dependent Autophagy of Intracellular Salmonella Typhimurium. Cell Host Microbe. 12:778-790. doi:10.1016/j.chom.2012.10.019.

Hung, Y.-H., L.M.-W. Chen, J.-Y. Yang, and W. Yuan Yang. 2013. Spatiotemporally controlled induction of autophagy-mediated lysosome turnover. Nat. Commun. 4:2111. doi:10.1038/ncomms3111.

Ireland, J.M., and E.R. Unanue. 2011. Autophagy in antigen-presenting cells results in presentation of citrullinated peptides to CD4 T cells. J. Exp. Med. 208:2625-2632. doi:10.1084/jem.20110640.

Itakura, E., and N. Mizushima. 2010. Characterization of autophagosome formation site by a hierarchical analysis of mammalian Atg proteins. Autophagy. 6:764-776.

Jackson, W.T., T.H. Giddings Jr, M.P. Taylor, S. Mulinyawe, M. Rabinovitch, R.R. Kopito, and K. Kirkegaard. 2005. Subversion of cellular autophagosomal machinery by RNA viruses. PLoS Biol. 3:e156. doi:10.1371/journal.pbio.0030156. 
Jagannath, C., D.R. Lindsey, S. Dhandayuthapani, Y. Xu, R.L. Hunter, and N.T. Eissa. 2009. Autophagy enhances the efficacy of BCG vaccine by increasing peptide presentation in mouse dendritic cells. Nat. Med. 15:267-276. doi:10.1038/nm.1928.

Jia, K., C. Thomas, M. Akbar, Q. Sun, B. Adams-Huet, C. Gilpin, and B. Levine. 2009. Autophagy genes protect against Salmonella typhimurium infection and mediate insulin signaling-regulated pathogen resistance. Proc. Natl. Acad. Sci. 106:14564-14569. doi:10.1073/pnas.0813319106.

Jia, W., H.H. Pua, Q.-J. Li, and Y.-W. He. 2011. Autophagy regulates endoplasmic reticulum homeostasis and calcium mobilization in T lymphocytes. J. Immunol. Baltim. Md 1950. 186:1564-1574. doi:10.4049/jimmunol.1001822.

Jin, Y., C. Sun, L. Feng, P. Li, L. Xiao, Y. Ren, D. Wang, C. Li, and L. Chen. 2014. Regulation of SIV antigen-specific CD4+ T cellular immunity via autophagosome-mediated MHC II molecule-targeting antigen presentation in mice. PloS One. 9:e93143. doi:10.1371/journal.pone.0093143.

Johnstone, C., M. Ramos, B. García-Barreno, D. López, J.A. Melero, and M. Del Val. 2012. Exogenous, TAP-independent lysosomal presentation of a respiratory syncytial virus CTL epitope. Immunol. Cell Biol. 90:978-982. doi:10.1038/icb.2012.43.

Jounai, N., K. Kobiyama, M. Shiina, K. Ogata, K.J. Ishii, and F. Takeshita. 2011. NLRP4 Negatively Regulates Autophagic Processes through an Association with Beclin1. J. Immunol. 186:1646-1655. doi:10.4049/jimmunol.1001654.

Jounai, N., F. Takeshita, K. Kobiyama, A. Sawano, A. Miyawaki, K.-Q. Xin, K.J. Ishii, T. Kawai, S. Akira, K. Suzuki, and K. Okuda. 2007. The Atg5 Atg12 conjugate associates with innate antiviral immune responses. Proc. Natl. Acad. Sci. U. S. A. 104:14050-14055. doi:10.1073/pnas.0704014104.

Kabeya, Y., N. Mizushima, T. Ueno, A. Yamamoto, T. Kirisako, T. Noda, E. Kominami, Y. Ohsumi, and T. Yoshimori. 2000. LC3, a mammalian homologue of yeast Apg8p, is localized in autophagosome membranes after processing. EMBO J. 19:5720-5728. doi:10.1093/emboj/19.21.5720.

Kageyama, S., H. Omori, T. Saitoh, T. Sone, J.-L. Guan, S. Akira, F. Imamoto, T. Noda, and T. Yoshimori. 2011. The LC3 recruitment mechanism is separate from Atg9L1-dependent membrane formation in the autophagic response against Salmonella. Mol. Biol. Cell. 22:2290-2300. doi:10.1091/mbc.E10-11-0893.

Kasai, M., I. Tanida, T. Ueno, E. Kominami, S. Seki, T. Ikeda, and T. Mizuochi. 2009. Autophagic compartments gain access to the MHC class II compartments in thymic epithelium. J. Immunol. Baltim. Md 1950. 183:7278-7285. doi:10.4049/jimmunol.0804087.

Kawai, T., and S. Akira. 2009. The roles of TLRs, RLRs and NLRs in pathogen recognition. Int. Immunol. 21:317-337. doi:10.1093/intimm/dxp017.

Kawai, T., and S. Akira. 2010. The role of pattern-recognition receptors in innate immunity: update on Toll-like receptors. Nat. Immunol. 11:373-384. doi:10.1038/ni.1863.

Keller, C.W., C. Fokken, S.G. Turville, A. Lünemann, J. Schmidt, C. Münz, and J.D. Lünemann. 2011. TNF- $\alpha$ Induces Macroautophagy and Regulates MHC Class II Expression in Human Skeletal Muscle Cells. J. Biol. Chem. 286:3970-3980. doi:10.1074/jbc.M110.159392.

Kim, P.K., D.W. Hailey, R.T. Mullen, and J. Lippincott-Schwartz. 2008. Ubiquitin signals 
autophagic degradation of cytosolic proteins and peroxisomes. Proc. Natl. Acad. Sci. U. S. A. 105:20567-20574. doi:10.1073/pnas.0810611105.

Kobayashi, S., T. Kojidani, H. Osakada, A. Yamamoto, T. Yoshimori, Y. Hiraoka, and T. Haraguchi. 2010. Artificial induction of autophagy around polystyrene beads in nonphagocytic cells. Autophagy. 6:36-45.

Konno, H., K. Konno, and G.N. Barber. 2013. Cyclic dinucleotides trigger ULK1 (ATG1) phosphorylation of STING to prevent sustained innate immune signaling. Cell. 155:688-698. doi:10.1016/j.cell.2013.09.049.

Kovacs, J.R., C. Li, Q. Yang, G. Li, I.G. Garcia, S. Ju, D.G. Roodman, J.J. Windle, X. Zhang, and B. Lu. 2012. Autophagy promotes T-cell survival through degradation of proteins of the cell death machinery. Cell Death Differ. 19:144-152. doi:10.1038/cdd.2011.78.

Kristensen, A.R., S. Schandorff, M. Høyer-Hansen, M.O. Nielsen, M. Jäättelä, J. Dengjel, and J.S. Andersen. 2008. Ordered organelle degradation during starvation-induced autophagy. Mol. Cell. Proteomics MCP. 7:2419-2428. doi:10.1074/mcp.M800184-MCP200.

Kyei, G.B., C. Dinkins, A.S. Davis, E. Roberts, S.B. Singh, C. Dong, L. Wu, E. Kominami, T. Ueno, A. Yamamoto, M. Federico, A. Panganiban, I. Vergne, and V. Deretic. 2009. Autophagy pathway intersects with HIV-1 biosynthesis and regulates viral yields in macrophages. J. Cell Biol. 186:255-268. doi:10.1083/jcb.200903070.

Lamkanfi, M., and V.M. Dixit. 2014. Mechanisms and functions of inflammasomes. Cell. 157:1013-1022. doi:10.1016/j.cell.2014.04.007.

Lassen, K.G., P. Kuballa, K.L. Conway, K.K. Patel, C.E. Becker, J.M. Peloquin, E.J. Villablanca, J.M. Norman, T.-C. Liu, R.J. Heath, M.L. Becker, L. Fagbami, H. Horn, J. Mercer, O.H. Yilmaz, J.D. Jaffe, A.F. Shamji, A.K. Bhan, S.A. Carr, M.J. Daly, H.W. Virgin, S.L. Schreiber, T.S. Stappenbeck, and R.J. Xavier. 2014. Atg16L1 T300A variant decreases selective autophagy resulting in altered cytokine signaling and decreased antibacterial defense. Proc. Natl. Acad. Sci. U. S. A. 111:7741-7746. doi:10.1073/pnas.1407001111.

Latz, E., T.S. Xiao, and A. Stutz. 2013. Activation and regulation of the inflammasomes. Nat. Rev. Immunol. 13:397-411. doi:10.1038/nri3452.

Lee, H.K., J.M. Lund, B. Ramanathan, N. Mizushima, and A. Iwasaki. 2007. Autophagy-dependent viral recognition by plasmacytoid dendritic cells. Science. 315:1398-1401. doi:10.1126/science.1136880.

Lee, H.K., L.M. Mattei, B.E. Steinberg, P. Alberts, Y.H. Lee, A. Chervonsky, N. Mizushima, S. Grinstein, and A. Iwasaki. 2010. In vivo requirement for Atg5 in antigen presentation by dendritic cells. Immunity. 32:227-239. doi:10.1016/j.immuni.2009.12.006.

Lei, Y., H. Wen, Y. Yu, D.J. Taxman, L. Zhang, D.G. Widman, K.V. Swanson, K.-W. Wen, B. Damania, C.B. Moore, P.M. Giguère, D.P. Siderovski, J. Hiscott, B. Razani, C.F. Semenkovich, X. Chen, and J.P.-Y. Ting. 2012. The mitochondrial proteins NLRX1 and TUFM form a complex that regulates type I interferon and autophagy. Immunity. 36:933-946. doi:10.1016/j.immuni.2012.03.025.

Leung, C.S., T.A. Haigh, L.K. Mackay, A.B. Rickinson, and G.S. Taylor. 2010. Nuclear location of an endogenously expressed antigen, EBNA1, restricts access to macroautophagy and the range of CD4 epitope display. Proc. Natl. Acad. Sci. U. S. A. 107:2165-2170. doi:10.1073/pnas.0909448107. 
Liang, Q., G.J. Seo, Y.J. Choi, M.-J. Kwak, J. Ge, M.A. Rodgers, M. Shi, B.J. Leslie, K.-P. Hopfner, T. Ha, B.-H. Oh, and J.U. Jung. 2014. Crosstalk between the cGAS DNA sensor and Beclin-1 autophagy protein shapes innate antimicrobial immune responses. Cell Host Microbe. 15:228-238. doi:10.1016/j.chom.2014.01.009.

Liang, X.H., L.K. Kleeman, H.H. Jiang, G. Gordon, J.E. Goldman, G. Berry, B. Herman, and B. Levine. 1998. Protection against Fatal Sindbis Virus Encephalitis by Beclin, a Novel Bcl-2-Interacting Protein. J. Virol. 72:8586-8596.

Li, B., Z. Lei, B.D. Lichty, D. Li, G.-M. Zhang, Z.-H. Feng, Y. Wan, and B. Huang. 2010. Autophagy facilitates major histocompatibility complex class I expression induced by IFN-y in B16 melanoma cells. Cancer Immunol. Immunother. Cll. 59:313-321. doi:10.1007/s00262-009-0752-1.

Li, Y., L.-X. Wang, G. Yang, F. Hao, W.J. Urba, and H.-M. Hu. 2008. Efficient cross-presentation depends on autophagy in tumor cells. Cancer Res. 68:6889-6895. doi:10.1158/0008-5472.CAN-08-0161.

De Luca, A., R.G. Iannitti, S. Bozza, R. Beau, A. Casagrande, C. D’Angelo, S. Moretti, C. Cunha, G. Giovannini, C. Massi-Benedetti, A. Carvalho, L. Boon, J.-P. Latgé, and L. Romani. 2012. CD4(+) T cell vaccination overcomes defective cross-presentation of fungal antigens in a mouse model of chronic granulomatous disease. J. Clin. Invest. 122:1816-1831. doi:10.1172/JCI60862.

Lupfer, C., P.G. Thomas, P.K. Anand, P. Vogel, S. Milasta, J. Martinez, G. Huang, M. Green, M. Kundu, H. Chi, R.J. Xavier, D.R. Green, M. Lamkanfi, C.A. Dinarello, P.C. Doherty, and T.-D. Kanneganti. 2013. Receptor interacting protein kinase 2-mediated mitophagy regulates inflammasome activation during virus infection. Nat. Immunol. 14:480-488. doi:10.1038/ni.2563.

Maejima, I., A. Takahashi, H. Omori, T. Kimura, Y. Takabatake, T. Saitoh, A. Yamamoto, M. Hamasaki, T. Noda, Y. Isaka, and T. Yoshimori. 2013. Autophagy sequesters damaged lysosomes to control lysosomal biogenesis and kidney injury. EMBO J. 32:2336-2347. doi:10.1038/emboj.2013.171.

Ma, J., C. Becker, C.A. Lowell, and D.M. Underhill. 2012. Dectin-1-triggered recruitment of light chain 3 protein to phagosomes facilitates major histocompatibility complex class II presentation of fungal-derived antigens. J. Biol. Chem. 287:34149-34156. doi:10.1074/jbc.M112.382812.

Ma, J., C. Becker, C. Reyes, and D.M. Underhill. 2014. Cutting edge: FYCO1 recruitment to dectin-1 phagosomes is accelerated by light chain 3 protein and regulates phagosome maturation and reactive oxygen production. J. Immunol. Baltim. Md 1950. 192:1356-1360. doi:10.4049/jimmunol.1302835.

Manjithaya, R., C. Anjard, W.F. Loomis, and S. Subramani. 2010. Unconventional secretion of Pichia pastoris Acb1 is dependent on GRASP protein, peroxisomal functions, and autophagosome formation. J. Cell Biol. 188:537-546. doi:10.1083/jcb.200911149.

Manzanillo, P.S., J.S. Ayres, R.O. Watson, A.C. Collins, G. Souza, C.S. Rae, D.S. Schneider, K. Nakamura, M.U. Shiloh, and J.S. Cox. 2013. The ubiquitin ligase parkin mediates resistance to intracellular pathogens. Nature. 501:512-516. doi:10.1038/nature12566.

Marshall, R.S., Li, F., Gemperline, D.C., Book, A.J., and Vierstra, R.D. (2015). Autophagic Degradation of the 26S Proteasome Is Mediated by the Dual ATG8/Ubiquitin Receptor RPN10 in Arabidopsis. Mol Cell 58, 1053-1066.

Marchiando, A.M., D. Ramanan, Y. Ding, L.E. Gomez, V.M. Hubbard-Lucey, K. Maurer, C. 
Wang, J.W. Ziel, N. van Rooijen, G. Nuñez, B.B. Finlay, I.U. Mysorekar, and K. Cadwell. 2013. A Deficiency in the Autophagy Gene Atg16L1 Enhances Resistance to Enteric Bacterial Infection. Cell Host Microbe. 14:216-224. doi:10.1016/j.chom.2013.07.013.

Martinez, J., J. Almendinger, A. Oberst, R. Ness, C.P. Dillon, P. Fitzgerald, M.O. Hengartner, and D.R. Green. 2011. Microtubule-associated protein 1 light chain 3 alpha (LC3)-associated phagocytosis is required for the efficient clearance of dead cells. Proc. Natl. Acad. Sci. U. S. A. 108:17396-17401. doi:10.1073/pnas.1113421108.

Martinez, J., Malireddi, R.K., Lu, Q., Cunha, L.D., Pelletier, S., Gingras, S., Orchard, R., Guan, J.L., Tan, H., Peng, J., et al. (2015). Molecular characterization of LC3-associated phagocytosis reveals distinct roles for Rubicon, NOX2 and autophagy proteins. Nat Cell Biol 17, 893-906.

Martins, I., Y. Wang, M. Michaud, Y. Ma, A.Q. Sukkurwala, S. Shen, O. Kepp, D. Métivier, L. Galluzzi, J.-L. Perfettini, L. Zitvogel, and G. Kroemer. 2014. Molecular mechanisms of ATP secretion during immunogenic cell death. Cell Death Differ. 21:79-91. doi:10.1038/cdd.2013.75.

Matsunaga, K., E. Morita, T. Saitoh, S. Akira, N.T. Ktistakis, T. Izumi, T. Noda, and T. Yoshimori. 2010. Autophagy requires endoplasmic reticulum targeting of the PI3-kinase complex via Atg14L. J. Cell Biol. 190:511-521. doi:10.1083/jcb.200911141.

Meunier, E., M.S. Dick, R.F. Dreier, N. Schürmann, D. Kenzelmann Broz, S. Warming, M. Roose-Girma, D. Bumann, N. Kayagaki, K. Takeda, M. Yamamoto, and P. Broz. 2014. Caspase-11 activation requires lysis of pathogen-containing vacuoles by IFN-induced GTPases. Nature. 509:366-370. doi:10.1038/nature13157.

Milan, E., Perini, T., Resnati, M., Orfanelli, U., Oliva, L., Raimondi, A., Cascio, P., Bachi, A., Marcatti, M., Ciceri, F., and Cenci, S. (2015). A plastic SQSTM1/p62-dependent autophagic reserve maintains proteostasis and determines proteasome inhibitor susceptibility in multiple myeloma cells. Autophagy 11, 1161-1178.

Miller, B.C., Z. Zhao, L.M. Stephenson, K. Cadwell, H.H. Pua, H.K. Lee, N.N. Mizushima, A. Iwasaki, Y.-W. He, W. Swat, and H.W. Virgin 4th. 2008. The autophagy gene ATG5 plays an essential role in B lymphocyte development. Autophagy. 4:309-314.

Mizushima, N., and M. Komatsu. 2011. Autophagy: renovation of cells and tissues. Cell. 147:728-741. doi:10.1016/j.cell.2011.10.026.

Mizushima, N., A. Yamamoto, M. Hatano, Y. Kobayashi, Y. Kabeya, K. Suzuki, T. Tokuhisa, Y. Ohsumi, and T. Yoshimori. 2001. Dissection of autophagosome formation using Apg5-deficient mouse embryonic stem cells. J. Cell Biol. 152:657-668.

Mortensen, M., E.J. Soilleux, G. Djordjevic, R. Tripp, M. Lutteropp, E. Sadighi-Akha, A.J. Stranks, J. Glanville, S. Knight, S.-E.W. Jacobsen, K.R. Kranc, and A.K. Simon. 2011. The autophagy protein Atg7 is essential for hematopoietic stem cell maintenance. $J$. Exp. Med. 208:455-467. doi:10.1084/jem.20101145.

Mostowy, S., V. Sancho-Shimizu, M.A. Hamon, R. Simeone, R. Brosch, T. Johansen, and P. Cossart. 2011. p62 and NDP52 proteins target intracytosolic Shigella and Listeria to different autophagy pathways. J. Biol. Chem. 286:26987-26995. doi:10.1074/jbc.M111.223610.

Murthy, A., Y. Li, I. Peng, M. Reichelt, A.K. Katakam, R. Noubade, M. Roose-Girma, J. 
DeVoss, L. Diehl, R.R. Graham, and M. van Lookeren Campagne. 2014. A Crohn's disease variant in Atg16l1 enhances its degradation by caspase 3. Nature. 506:456-462. doi:10.1038/nature13044.

Nakagawa, I., A. Amano, N. Mizushima, A. Yamamoto, H. Yamaguchi, T. Kamimoto, A. Nara, J. Funao, M. Nakata, K. Tsuda, S. Hamada, and T. Yoshimori. 2004. Autophagy defends cells against invading group A Streptococcus. Science. 306:1037-1040. doi:10.1126/science.1103966.

Nakahira, K., J.A. Haspel, V.A.K. Rathinam, S.-J. Lee, T. Dolinay, H.C. Lam, J.A. Englert, M. Rabinovitch, M. Cernadas, H.P. Kim, K.A. Fitzgerald, S.W. Ryter, and A.M.K. Choi. 2011. Autophagy proteins regulate innate immune responses by inhibiting the release of mitochondrial DNA mediated by the NALP3 inflammasome. Nat. Immunol. 12:222-230. doi:10.1038/ni.1980.

Nakatogawa, H., K. Suzuki, Y. Kamada, and Y. Ohsumi. 2009. Dynamics and diversity in autophagy mechanisms: lessons from yeast. Nat. Rev. Mol. Cell Biol. 10:458-467. doi:10.1038/nrm2708.

Narendra, D., A. Tanaka, D.-F. Suen, and R.J. Youle. 2008. Parkin is recruited selectively to impaired mitochondria and promotes their autophagy. J. Cell Biol. 183:795-803. doi:10.1083/jcb.200809125.

Nedjic, J., M. Aichinger, J. Emmerich, N. Mizushima, and L. Klein. 2008. Autophagy in thymic epithelium shapes the T-cell repertoire and is essential for tolerance. Nature. 455:396-400. doi:10.1038/nature07208.

Netea, M.G., F.L. van de Veerdonk, J.W.M. van der Meer, C.A. Dinarello, and L.A.B. Joosten. 2014. Inflammasome-Independent Regulation of IL-1-Family Cytokines. Annu. Rev. Immunol. doi:10.1146/annurev-immunol-032414-112306.

Ng, A.C.Y., J.M. Eisenberg, R.J.W. Heath, A. Huett, C.M. Robinson, G.J. Nau, and R.J. Xavier. 2011. Human leucine-rich repeat proteins: a genome-wide bioinformatic categorization and functional analysis in innate immunity. Proc. Natl. Acad. Sci. U. S. A. 108 Suppl 1:4631-4638. doi:10.1073/pnas.1000093107.

Novikoff, A.B. 1959. The proximal tubule cell in experimental hydronephrosis. J. Biophys. Biochem. Cytol. 6:136-138.

Nowag, H., B. Guhl, K. Thriene, S. Romao, U. Ziegler, J. Dengjel, and C. Münz. 2014. Macroautophagy Proteins Assist Epstein Barr Virus Production and Get Incorporated Into the Virus Particles. EBioMedicine. 1:116-125. doi:10.1016/j.ebiom.2014.11.007.

Ogawa, M., T. Yoshimori, T. Suzuki, H. Sagara, N. Mizushima, and C. Sasakawa. 2005. Escape of intracellular Shigella from autophagy. Science. 307:727-731. doi:10.1126/science.1106036.

Ohsumi, Y. 2014. Historical landmarks of autophagy research. Cell Res. 24:9-23. doi:10.1038/cr.2013.169.

Orvedahl, A., R.S. Jr, G. Xiao, A. Ng, Z. Zou, Y. Tang, M. Narimatsu, C. Gilpin, Q. Sun, M. Roth, C.V. Forst, J.L. Wrana, Y.E. Zhang, K. Luby-Phelps, R.J. Xavier, Y. Xie, and B. Levine. 2011. Image-based genome-wide siRNA screen identifies selective autophagy factors. Nature. 480:113-117. doi:10.1038/nature10546.

Orvedahl, A., S. MacPherson, R. Sumpter, Z. Tallóczy, Z. Zou, and B. Levine. 2010. Autophagy Protects against Sindbis Virus Infection of the Central Nervous System. Cell Host Microbe. 7:115-127. doi:10.1016/j.chom.2010.01.007. 
Paludan, C., D. Schmid, M. Landthaler, M. Vockerodt, D. Kube, T. Tuschl, and C. Münz. 2005. Endogenous MHC class II processing of a viral nuclear antigen after autophagy. Science. 307:593-596. doi:10.1126/science.1104904.

Parekh, V.V., L. Wu, K.L. Boyd, J.A. Williams, J.A. Gaddy, D. Olivares-Villagómez, T.L. Cover, W.-X. Zong, J. Zhang, and L. Van Kaer. 2013. Impaired autophagy, defective T cell homeostasis, and a wasting syndrome in mice with a T cell-specific deletion of Vps34. J. Immunol. Baltim. Md 1950. 190:5086-5101. doi:10.4049/jimmunol.1202071.

Pengo, N., M. Scolari, L. Oliva, E. Milan, F. Mainoldi, A. Raimondi, C. Fagioli, A. Merlini, E. Mariani, E. Pasqualetto, U. Orfanelli, M. Ponzoni, R. Sitia, S. Casola, and S. Cenci. 2013. Plasma cells require autophagy for sustainable immunoglobulin production. Nat. Immunol. 14:298-305. doi:10.1038/ni.2524.

Pilli, M., J. Arko-Mensah, M. Ponpuak, E. Roberts, S. Master, M.A. Mandell, N. Dupont, W. Ornatowski, S. Jiang, S.B. Bradfute, J.-A. Bruun, T.E. Hansen, T. Johansen, and V. Deretic. 2012. TBK-1 Promotes Autophagy-Mediated Antimicrobial Defense by Controlling Autophagosome Maturation. Immunity. 37:223-234. doi:10.1016/j.immuni.2012.04.015.

Plantinga, T.S., T.O. Crisan, M. Oosting, F.L. van de Veerdonk, D.J. de Jong, D.J. Philpott, J.W.M. van der Meer, S.E. Girardin, L.A.B. Joosten, and M.G. Netea. 2011. Crohn's disease-associated ATG16L1 polymorphism modulates pro-inflammatory cytokine responses selectively upon activation of NOD2. Gut. 60:1229-1235. doi:10.1136/gut.2010.228908.

Pua, H.H., I. Dzhagalov, M. Chuck, N. Mizushima, and Y.-W. He. 2007. A critical role for the autophagy gene Atg5 in T cell survival and proliferation. J. Exp. Med. 204:25-31. doi:10.1084/jem.20061303.

Pua, H.H., J. Guo, M. Komatsu, and Y.-W. He. 2009. Autophagy is essential for mitochondrial clearance in mature T lymphocytes. J. Immunol. Baltim. Md 1950. 182:4046-4055. doi:10.4049/jimmunol.0801143.

Puleston, D.J., Zhang, H., Powell, T.J., Lipina, E., Sims, S., Panse, I., Watson, A.S., Cerundolo, V., Townsend, A.R., Klenerman, P., and Simon, A.K. (2014). Autophagy is a critical regulator of memory $\mathrm{CD} 8^{+} \mathrm{T}$ cell formation. Elife 3.

Py, B.F., M.M. Lipinski, and J. Yuan. 2007. Autophagy limits Listeria monocytogenes intracellular growth in the early phase of primary infection. Autophagy. 3:117-125.

Razani, B., C. Feng, T. Coleman, R. Emanuel, H. Wen, S. Hwang, J.P. Ting, H.W. Virgin, M.B. Kastan, and C.F. Semenkovich. 2012. Autophagy links inflammasomes to atherosclerotic progression. Cell Metab. 15:534-544. doi:10.1016/j.cmet.2012.02.011.

Rioux, J.D., R.J. Xavier, K.D. Taylor, M.S. Silverberg, P. Goyette, A. Huett, T. Green, P. Kuballa, M.M. Barmada, L.W. Datta, Y.Y. Shugart, A.M. Griffiths, S.R. Targan, A.F. Ippoliti, E.-J. Bernard, L. Mei, D.L. Nicolae, M. Regueiro, L.P. Schumm, A.H. Steinhart, J.I. Rotter, R.H. Duerr, J.H. Cho, M.J. Daly, and S.R. Brant. 2007. Genome-wide association study identifies new susceptibility loci for Crohn disease and implicates autophagy in disease pathogenesis. Nat. Genet. 39:596-604. doi:10.1038/ng2032.

Romao, S., M. Gannage, and C. Münz. 2013a. Checking the garbage bin for problems in the house, or how autophagy assists in antigen presentation to the immune system. Semin. Cancer Biol. 23:391-396. doi:10.1016/j.semcancer.2013.03.001.

Romao, S., N. Gasser, A.C. Becker, B. Guhl, M. Bajagic, D. Vanoaica, U. Ziegler, J. Roesler, 
J. Dengjel, J. Reichenbach, and C. Münz. 2013b. Autophagy proteins stabilize pathogen-containing phagosomes for prolonged MHC II antigen processing. J. Cell Biol. 203:757-766. doi:10.1083/jcb.201308173.

Saitoh, T., N. Fujita, T. Hayashi, K. Takahara, T. Satoh, H. Lee, K. Matsunaga, S. Kageyama, H. Omori, T. Noda, N. Yamamoto, T. Kawai, K. Ishii, O. Takeuchi, T. Yoshimori, and S. Akira. 2009. Atg9a controls dsDNA-driven dynamic translocation of STING and the innate immune response. Proc. Natl. Acad. Sci. U. S. A. 106:20842-20846. doi:10.1073/pnas.0911267106.

Saitoh, T., N. Fujita, M.H. Jang, S. Uematsu, B.-G. Yang, T. Satoh, H. Omori, T. Noda, N. Yamamoto, M. Komatsu, K. Tanaka, T. Kawai, T. Tsujimura, O. Takeuchi, T. Yoshimori, and S. Akira. 2008. Loss of the autophagy protein Atg16L1 enhances endotoxin-induced IL-1beta production. Nature. 456:264-268. doi:10.1038/nature07383.

Sanjuan, M.A., C.P. Dillon, S.W.G. Tait, S. Moshiach, F. Dorsey, S. Connell, M. Komatsu, K. Tanaka, J.L. Cleveland, S. Withoff, and D.R. Green. 2007. Toll-like receptor signalling in macrophages links the autophagy pathway to phagocytosis. Nature. 450:1253-1257. doi:10.1038/nature06421.

Schmid, D., M. Pypaert, and C. Münz. 2007. Antigen-loading compartments for major histocompatibility complex class II molecules continuously receive input from autophagosomes. Immunity. 26:79-92. doi:10.1016/j.immuni.2006.10.018.

Shaw, S.Y., K. Tran, A.B. Castoreno, J.M. Peloquin, K.G. Lassen, B. Khor, L.N. Aldrich, P.H. Tan, D.B. Graham, P. Kuballa, G. Goel, M.J. Daly, A.F. Shamji, S.L. Schreiber, and R.J. Xavier. 2013. Selective modulation of autophagy, innate immunity, and adaptive immunity by small molecules. ACS Chem. Biol. 8:2724-2733. doi:10.1021/cb400352d.

Shelly, S., N. Lukinova, S. Bambina, A. Berman, and S. Cherry. 2009. Autophagy Is an Essential Component of Drosophila Immunity against Vesicular Stomatitis Virus. Immunity. 30:588-598. doi:10.1016/j.immuni.2009.02.009.

Shen, S., M. Niso-Santano, S. Adjemian, T. Takehara, S.A. Malik, H. Minoux, S. Souquere, G. Mariño, S. Lachkar, L. Senovilla, L. Galluzzi, O. Kepp, G. Pierron, M.C. Maiuri, H. Hikita, R. Kroemer, and G. Kroemer. 2012. Cytoplasmic STAT3 Represses Autophagy by Inhibiting PKR Activity. Mol. Cell. 48:667-680. doi:10.1016/j.molcel.2012.09.013.

Shi, C.-S., K. Shenderov, N.-N. Huang, J. Kabat, M. Abu-Asab, K.A. Fitzgerald, A. Sher, and J.H. Kehrl. 2012. Activation of autophagy by inflammatory signals limits IL-1 $\beta$ production by targeting ubiquitinated inflammasomes for destruction. Nat. Immunol. 13:255-263. doi:10.1038/ni.2215.

Shoji-Kawata, S., R. Sumpter, M. Leveno, G.R. Campbell, Z. Zou, L. Kinch, A.D. Wilkins, Q. Sun, K. Pallauf, D. Macduff, C. Huerta, H.W. Virgin, J.B. Helms, R. Eerland, S.A. Tooze, R. Xavier, D.J. Lenschow, A. Yamamoto, D. King, O. Lichtarge, N.V. Grishin, S.A. Spector, D.V. Kaloyanova, and B. Levine. 2013. Identification of a candidate therapeutic autophagy-inducing peptide. Nature. doi:10.1038/nature11866.

Singh, S.B., A.S. Davis, G.A. Taylor, and V. Deretic. 2006. Human IRGM induces autophagy to eliminate intracellular mycobacteria. Science. 313:1438-1441. doi:10.1126/science.1129577.

Sou, Y., S. Waguri, J. Iwata, T. Ueno, T. Fujimura, T. Hara, N. Sawada, A. Yamada, N. Mizushima, Y. Uchiyama, E. Kominami, K. Tanaka, and M. Komatsu. 2008. The Atg8 conjugation system is indispensable for proper development of autophagic isolation 
membranes in mice. Mol. Biol. Cell. 19:4762-4775. doi:10.1091/mbc.E08-03-0309.

Tal, M.C., M. Sasai, H.K. Lee, B. Yordy, G.S. Shadel, and A. Iwasaki. 2009. Absence of autophagy results in reactive oxygen species-dependent amplification of RLR signaling. Proc. Natl. Acad. Sci. U. S. A. 106:2770-2775. doi:10.1073/pnas.0807694106.

Tang, D., R. Kang, K.M. Livesey, C.-W. Cheh, A. Farkas, P. Loughran, G. Hoppe, M.E. Bianchi, K.J. Tracey, H.J. Zeh, and M.T. Lotze. 2010. Endogenous HMGB1 regulates autophagy. J. Cell Biol. 190:881-892. doi:10.1083/jcb.200911078.

Tey, S.-K., and R. Khanna. 2012. Autophagy mediates transporter associated with antigen processing-independent presentation of viral epitopes through MHC class I pathway. Blood. 120:994-1004. doi:10.1182/blood-2012-01-402404.

Thorburn, J., H. Horita, J. Redzic, K. Hansen, A.E. Frankel, and A. Thorburn. 2009. Autophagy regulates selective HMGB1 release in tumor cells that are destined to die. Cell Death Differ. 16:175-183. doi:10.1038/cdd.2008.143.

Thurston, T.L.M., M.P. Wandel, N. von Muhlinen, A. Foeglein, and F. Randow. 2012. Galectin 8 targets damaged vesicles for autophagy to defend cells against bacterial invasion. Nature. 482:414-418. doi:10.1038/nature10744.

Travassos, L.H., L.A.M. Carneiro, M. Ramjeet, S. Hussey, Y.-G. Kim, J.G. Magalhães, L. Yuan, F. Soares, E. Chea, L. Le Bourhis, I.G. Boneca, A. Allaoui, N.L. Jones, G. Nuñez, S.E. Girardin, and D.J. Philpott. 2010. Nod1 and Nod2 direct autophagy by recruiting ATG16L1 to the plasma membrane at the site of bacterial entry. Nat. Immunol. 11:55-62. doi:10.1038/ni.1823.

Uhl, M., O. Kepp, H. Jusforgues-Saklani, J.-M. Vicencio, G. Kroemer, and M.L. Albert. 2009. Autophagy within the antigen donor cell facilitates efficient antigen cross-priming of virus-specific CD8+ T cells. Cell Death Differ. 16:991-1005. doi:10.1038/cdd.2009.8.

Wang, C., G.R. Mendonsa, J.W. Symington, Q. Zhang, K. Cadwell, H.W. Virgin, and I.U. Mysorekar. 2012. Atg16L1 deficiency confers protection from uropathogenic Escherichia coli infection in vivo. Proc. Natl. Acad. Sci. U. S. A. 109:11008-11013. doi:10.1073/pnas.1203952109.

Watson, R.O., P.S. Manzanillo, and J.S. Cox. 2012. Extracellular M. tuberculosis DNA Targets Bacteria for Autophagy by Activating the Host DNA-Sensing Pathway. Cell. 150:803-815. doi:10.1016/j.cell.2012.06.040.

Welchman, R.L., C. Gordon, and R.J. Mayer. 2005. Ubiquitin and ubiquitin-like proteins as multifunctional signals. Nat. Rev. Mol. Cell Biol. 6:599-609. doi:10.1038/nrm1700.

Wenger, T., S. Terawaki, V. Camosseto, R. Abdelrassoul, A. Mies, N. Catalan, N. Claudio, G. Clavarino, A. de Gassart, F. de A. Rigotti, E. Gatti, and P. Pierre. 2012. Autophagy inhibition promotes defective neosynthesized proteins storage in ALIS, and induces redirection toward proteasome processing and $\mathrm{MHCl}$-restricted presentation. Autophagy. 8:350-363. doi:10.4161/auto.18806.

Wen, H., D. Gris, Y. Lei, S. Jha, L. Zhang, M.T.-H. Huang, W.J. Brickey, and J.P.-Y. Ting. 2011. Fatty acid-induced NLRP3-ASC inflammasome activation interferes with insulin signaling. Nat. Immunol. 12:408-415. doi:10.1038/ni.2022.

Willinger, T., and R.A. Flavell. 2012. Canonical autophagy dependent on the class III phosphoinositide-3 kinase Vps34 is required for naive T-cell homeostasis. Proc. Natl. Acad. Sci. U. S. A. 109:8670-8675. doi:10.1073/pnas.1205305109. 
Xu, X., Araki, K., Li, S., Han, J.H., Ye, L., Tan, W.G., Konieczny, B.T., Bruinsma, M.W., Martinez, J., Pearce, E.L., et al. (2014). Autophagy is essential for effector CD8 ${ }^{+} \mathrm{T}$ cell survival and memory formation. Nat Immunol 15, 1152-1161.

Xu, Y., C. Jagannath, X.-D. Liu, A. Sharafkhaneh, K.E. Kolodziejska, and N.T. Eissa. 2007. Toll-like receptor 4 is a sensor for autophagy associated with innate immunity. Immunity. 27:135-144. doi:10.1016/j.immuni.2007.05.022.

Yanai, H., A. Matsuda, J. An, R. Koshiba, J. Nishio, H. Negishi, H. Ikushima, T. Onoe, H. Ohdan, N. Yoshida, and T. Taniguchi. 2013. Conditional ablation of HMGB1 in mice reveals its protective function against endotoxemia and bacterial infection. Proc. Natl. Acad. Sci. U. S. A. 110:20699-20704. doi:10.1073/pnas.1320808110.

Yano, T., S. Mita, H. Ohmori, Y. Oshima, Y. Fujimoto, R. Ueda, H. Takada, W.E. Goldman, K. Fukase, N. Silverman, T. Yoshimori, and S. Kurata. 2008. Autophagic control of listeria through intracellular innate immune recognition in drosophila. Nat. Immunol. 9:908-916. doi:10.1038/ni.1634.

Ye, W., Y. Xing, C. Paustian, R. van de Ven, T. Moudgil, T.L. Hilton, B.A. Fox, W.J. Urba, W. Zhao, and H.-M. Hu. 2014. Cross-presentation of viral antigens in dribbles leads to efficient activation of virus-specific human memory T cells. J. Transl. Med. 12:100. doi:10.1186/1479-5876-12-100.

Yoneyama, M., K. Onomoto, M. Jogi, T. Akaboshi, and T. Fujita. 2015. Viral RNA detection by RIG-I-like receptors. Curr. Opin. Immunol. 32C:48-53. doi:10.1016/j.coi.2014.12.012.

Yordy, B., M.C. Tal, K. Hayashi, O. Arojo, and A. Iwasaki. 2013. Autophagy and selective deployment of Atg proteins in antiviral defense. Int. Immunol. 25:1-10. doi:10.1093/intimm/dxs101.

Zhao, Z., B. Fux, M. Goodwin, I.R. Dunay, D. Strong, B.C. Miller, K. Cadwell, M.A. Delgado, M. Ponpuak, K.G. Green, R.E. Schmidt, N. Mizushima, V. Deretic, L.D. Sibley, and H.W. Virgin. 2008. Autophagosome-independent essential function for the autophagy protein Atg5 in cellular immunity to intracellular pathogens. Cell Host Microbe. 4:458-469. doi:10.1016/j.chom.2008.10.003.

Zhou, R., A.S. Yazdi, P. Menu, and J. Tschopp. 2011. A role for mitochondria in NLRP3 inflammasome activation. Nature. 469:221-225. doi:10.1038/nature09663. 
Ubiquitin-dependent

Xenophagy
LC3-associated phagocytosis (LAP) in phagocytes

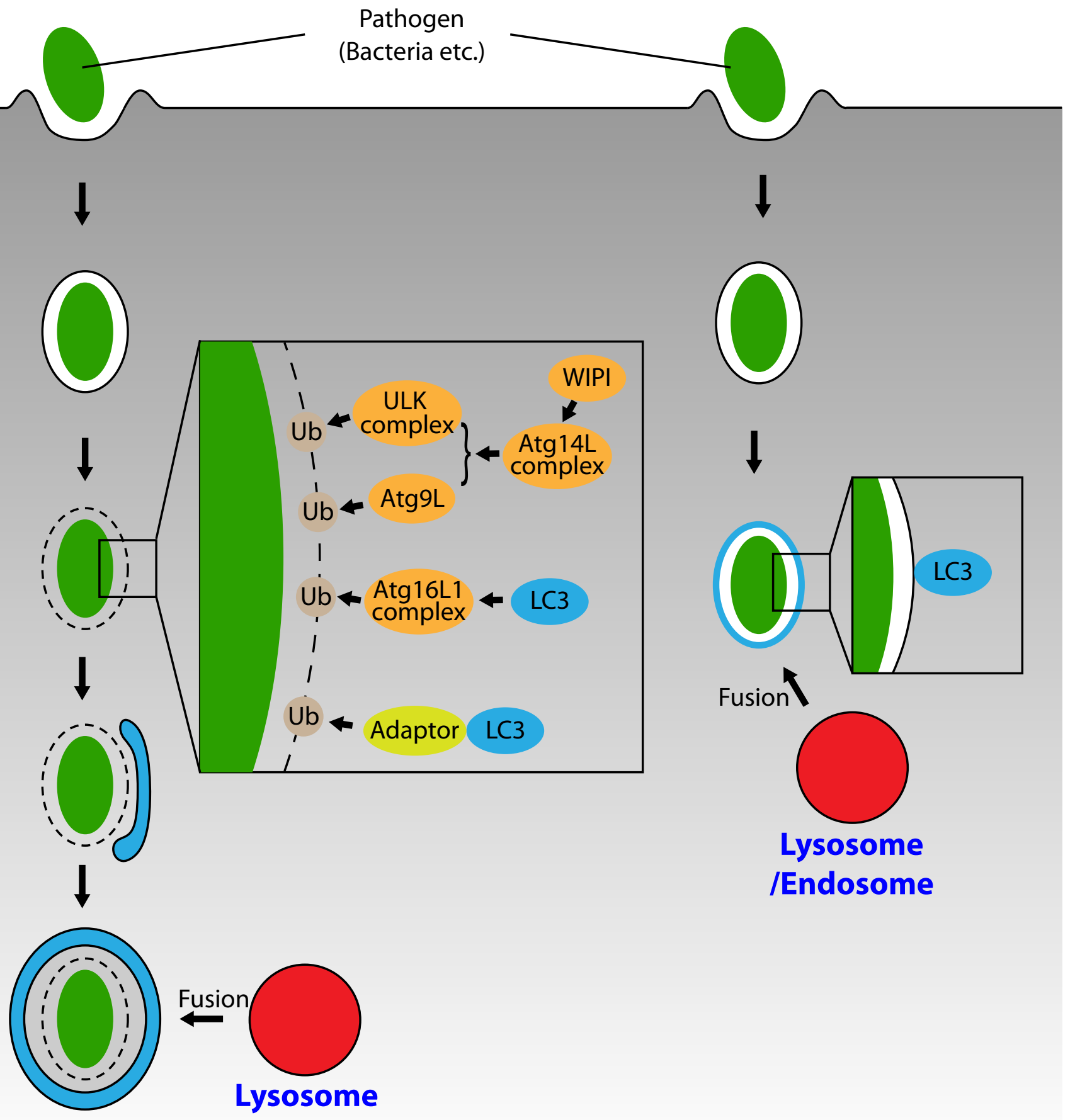




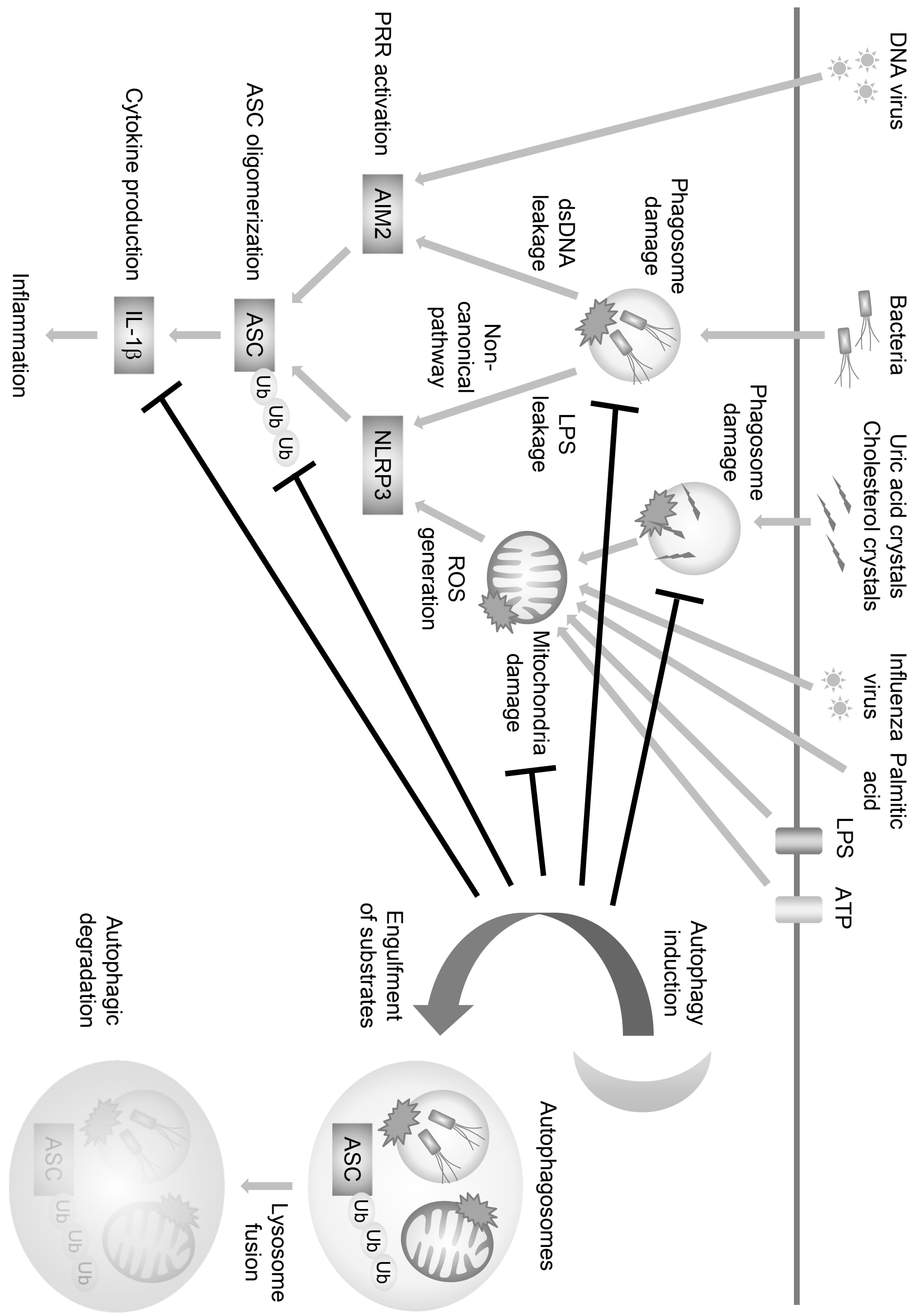


Figure 4

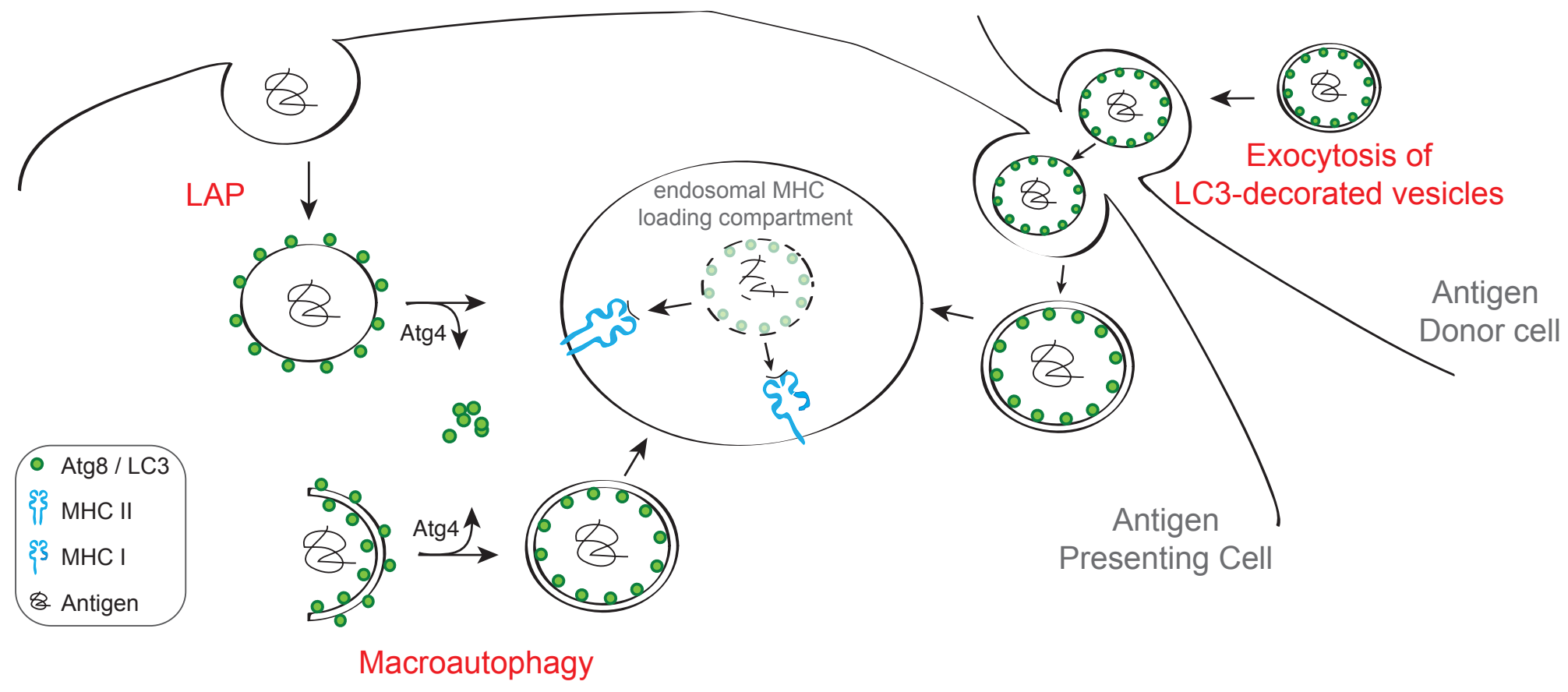

